\title{
El Método COPE para mejorar el cuidado de la atención: La experiencia de la Asociación para la Planificación Familiar de Kenia
}

Janet Bradley

Judith Bruce

Population Council

Soledad Diaz

Carlos Huezo

Kalimi Mworia

Follow this and additional works at: https://knowledgecommons.popcouncil.org/departments_sbsr-pgy

Part of the Family, Life Course, and Society Commons, International Public Health Commons, Public Health Education and Promotion Commons, and the Women's Health Commons How does access to this work benefit you? Let us know!

\section{Recommended Citation}

Bradley, Janet, Judith Bruce, Soledad Diaz, Carlos Huezo, and Kalimi Mworia. 1998. "El Método COPE para mejorar el cuidado de la atención: La experiencia de la Asociación para la Planificación Familiar de Kenia," Quality/Calidad/Qualité no. 9. New York: Population Council. 
Calidad/Quality/Qualité, una publicación del Population Council, resalta ejemplos de programas de planificación familiar y salud reproductiva que se esmeran por dar servicios de alta calidad. Esta serie es parte del Programa Robert H. Ebert en Temas Críticos en Salud Reproductiva y Población, el cual, mediante esfuerzos cientificos y prácticos, busca mejorar y expandir el alcance y la calidad de los servicios en salud reproductiva. Los fundamentos filosóficos del programa y de esta serie, parten de que las mujeres y sus parejas tienen derecho a recibir de los proveedores de servicios de salud reproductiva un trato respetuoso, información, continuidad en la atención y la presentación de opciones para elegir un método anticonceptivo. Los folletos reflejan uno de estos elementos necesarios para mejorar la calidad de los programas de planificación familiar.

Los proyectos para la documentación de la serie Calidad/Quality/Qualité los selecciona un Comité Asesor integrado por personas con una amplia experiencia en el campo de la salud reproductiva y comprometidas con el mejoramiento de la calidad de atención de los servicios. Estos proyectos muestran avances importantes en uno o más de los siguientes aspectos: ampliar la variedad de métodos anticonceptivos y tecnologías disponibles; suministrar la información que los clientes necesitan para tomar decisiones informadas sobre el manejo de su propia salud; reforzar la calidad de la interacción cliente/ proveedor y favorecer el contacto constante entre proveedores y clientes; ensayar estrategias innovadoras para mejorar la capacidad gerencial de los directivos y las habilidades técnicas de los proveedores de servicios de diferentes niveles de atención; expandir la gama de servicios y la información suministrada más allá de lo que usualmente se llama "planificación familiar"; y proporcionar atención en salud reproductiva a grupos desfavorecidos y sin acceso a los servicios.

Ninguno de los proyectos documentados en estas series se ofrece como un modelo para replicar. Por el contrario, cada uno está presentado como un ejemplo creativo inusual de valores, objetivos e implementación. Las "experiencias de aprendizaje" demuestran la actitud de autocritica que se requiere para anticipar las necesidades de servicios de los clientes y encontrar los medios para satisfacerlas con los recursos existentes. Esta postura reflexiva se ejemplifica mediante la voluntad de responder tanto a cambios de las necesidades de los clientes como de transformaciones sociales y económicas más amplias que afectan a las sociedades. Creemos que documentar las decisiones cruciales que estos programas han tomado ayudará a reforzar la creencia de que la satisfacción personal con los servicios de salud reproductiva, está íntimamente ligada con el cumplimento de metas sociales más amplias en salud y población.

La publicación de la edición original en inglés de Calidad/Quality/Qualité fue posible gracias al apoyo de la Fundación Ford, la Fundación John D. y Catherine T. MacArthur y el Fondo de las Naciones Unidas para Actividades de Población (FNUAP).

La edición en español fue financiada por el proyecto INOPAL III (Investigación Operativa y Asistencia Técnica en Planificación Familiar y Salud Reproductiva en América Latina y el Caribe) que a su vez es financiado por la Agencia Internacional para el Desarrollo de los Estados Unidos (USAID) mediante el contrato No. CCP-95-C-00-00007-00.

Traducción al español:

Responsable de la publicación:
Araceli Fernández

Silvia Llaguno

Número Nueve 1998 ISSN 1097-8194 CopyrightO1998 por The Population Council, Inc. 


\title{
El Método COPE para Mejorar el Cuidado de la Atención: La Experiencia de la Asociación para la Planificación Familiar de Kenia
}

\author{
por Janet Bradley \\ Introducción de Judith Bruce, Soledad Díaz, y Carlos Huezo \\ Epilogo de Kalimi Mworia
}

\begin{abstract}
Aviso: Esta es la primera de varias ediciones de Quality/Calidad/Qualité que describirá métodos concebidos para ayudar tanto a los directores como al personal de los programas de planificación familiar a efectuar una evaluación propia de la calidad de los servicios que prestan. Estas herramientas dan a los patrocinadores de los programas la oportunidad de identificar las deficiencias en su entorno de servicio y proponer soluciones. En este número, nos concentraremos en el COPE (Client-Oriented, Provider-Efficient) de AVSC Internacional, una herramienta de evaluación que ya se ha aplicado en 35 paises.
\end{abstract}

\section{Introducción}

La Conferencia Internacional de Población y Desarrollo (CIPD) propugnó un enfoque centrado en la demanda para el suministro de servicios, colocando así necesidades del individuo en la parte neural de todos los programas de planificación familiar y salud reproductiva. En última instancia, los prestadores de atención de primera línea son quienes asumen la responsabilidad de llevar a efecto lo dicho en El Cairo. Al adoptar un enfoque orientado a la demanda, los prestadores ahora tienen que estar conscientes del contexto social y las necesidades particulares de sus usuarios, además de respetar sus derechos y su capacidad para tomar decisiones razonadas. Sin embargo, en la mayoria de los casos, nada de lo incluido en la formación que reciben los prestadores -ya no se diga la estructura dentro de la cual se desempeñan- los ha preparado para conducirse de esta manera. Más aún, cuando nadie respeta las capacidades o derechos de los prestadores ¿cómo puede esperarse que ellos establezcan una relación afectiva con los derechos de sus usuarios y se interesen en estos derechos?

La responsabilidad de muchas de las limitaciones mostradas por el personal clínico recae sobre los directivos de los programas. Los prestadores no sólo reciben directrices técnicas y formación insuficientes o inadecuadas, sino que los supervisores suelen asumir una postura de crítica y tratan sólo los temas relacionados con la aptitud técnica y del logro de objetivos cuantitativos de los programas. Al personal clínico no se le permite, por lo general, contribuir en la definición de politicas y estrategias; rara vez se muestra interés en sus opiniones e intereses y casi siempre se pasan por alto. Empero, al terminar el día, son ellos quienes asumen la responsabilidad por las deficiencias en el cumplimiento del programa y la mala calidad de la atención resultante.

El método COPE de AVSC Internacional y la audaz, y en ocasiones rígida, aplicación que de éste ha hecho la Asociación para la Planificación Familiar de Kenia (FPAK) brindan un ejemplo maravilloso del aspecto real del proceso para mejorar la atención. Su aspecto es el de la experimentación. Aparece como un proceso de reconocer errores pasados de todo el sistema -sin culpar a nadie-, y evoca una voluntad de empezar de nuevo, de intentar otra vez y de seguir avanzando.

Aunque quizá el COPE no sea la única forma para que los prestadores participen activamente en la determinación de cómo puede mejorarse la atención, sí es un enfoque que ha demostrado la capacidad de los individuos y las 
organizaciones para encontrar soluciones prácticas a una amplia gama de problemas. En el ejemplo keniano presentado en este texto, el COPE se ha aplicado con flexibilidad e imaginación. Los directores principales han debido relajar su control sobre el método, con el resultado de que el personal clinico ha llegado a considerar al COPE como una herramienta propia, con la cual ellos pueden realizar cambios y emplearla para dar un mejor servicio a sus usuarios y aumentar su propio nivel de satisfacción laboral.

El COPE supone un proceso que otorga poder legitimo a los prestadores y al personal clínico, y se basa en la noción de los derechos de los usuarios; dota a los prestadores de más control sobre su entorno, mayor margen de iniciativa y más autoridad sobre los elementos necesarios, tales como suministros y aspectos financieros fundamentales. En suma, les permite hacer juicios y asumir la responsabilidad fuera de limites jerárquicos estrictos. En segundo lugar, les concede a los prestadores sentir una identificación natural con sus usuarios, entender su sensación de impotencia, exclusión y frustración. Algunas veces, los prestadores mismos son usuarios, y quizá eligieron trabajar en una profesión de servicio porque deseaban ayudar a otros. Por desgracia, a la fecha, pocas técnicas de gestión han reconocido o aprovechado esta afinidad natural. La aplicación del COPE ha promovido, además, una voluntad de hablar abiertamente sobre varios puntos antes "indecibles": por ejemplo, los malos niveles de inocuidad en contra de las infecciones en muchas clinicas de planificación familiar y el énfasis del programa en métodos a largo plazo, a menudo invasivos como el DIU, medicamentos inyectables y la contracepción quirúrgica voluntaria y permanente, en un entorno de niveles crecientes de enfermedades de transmisión sexual, incluso el VIH y el SIDA.

En el papel, el COPE parece concentrado en la clínica lo que lleva a la pregunta: ¿cómo puede la aplicación del COPE, que se realiza en clínicas por separado, producir un cambio sistemático? El COPE convalida, no obstante, la retórica de la CIPD al reforzar mensajes que empiezan a filtrarse en el panorama: la importancia de la elección del método, la de ofrecer información más completa, la de carácter confidencial y del derecho a la intimidad del individuo, y la fundamental de recibir una atención que no implique riesgos. En Kenia, la estrecha colaboración entre la FPAK y el Ministerio de Salud, así como la asociación generalmente cordial entre el Estado y las organizaciones no gubernamentales en una atmósfera propicia para la experimentación son ejemplos de este proceso; en ese país se realizó además el primer estudio de análisis situacional. El resultado es que estos ejercicios de evaluación propia producen, en efecto, un mejoramiento en la calidad de todo el sistema. El compromiso de la organización patrocinadora permite el avance del proceso de cambio y su entusiasmo en torno al método COPE, han permitido que un ejercicio de autoevaluación se convierta en una fuerza dinámica de transformación que afectará a todo el sistema de salud. Hoy día, el mejoramiento en la calidad es no sólo un elemento fundamental del plan estratégico de la FPAK, sino del Plan Nacional de Ejecución para la Planificación Familiar, del Ministerio de Salud de Kenia (MSK).

Por último, la fuerza del proceso es testimonio de la honestidad de los prestadores de servicios y de su capacidad para convertirse en los motores del cambio. Mucho después del término de los estudios sobre las repercusiones de la calidad de la atención, de que las prioridades de los organismos de ayuda hayan cambiado y que las conclusiones de las conferencias internacionales se olviden, el punto fundamental duradero seguirá siendo los prestadores mismos. Ellos sólo desean levantarse por la mañana y sentirse bien al ir al trabajo y al realizarlo saber que es útil y valorado. Así, el COPE está dando justo en el blanco en cuanto a la movilización del personal clínico como grupo de representación para mejorar la atención y para lograr un sistema de salud más humanitario y sensible. 


\section{La Asociación de Planificación Familiar de Kenia}

La Asociación de Planificación Familiar de Kenia (FPAK) se inició en 1961 como un grupo de voluntarios cuyo objetivo era sensibilizar al Estado y a la comunidad acerca de la planificación familiar. En ese año, la FPAK se convirtió en la primera asociación de planificación familiar de África en unirse a la Federación Internacional de Planificación de la Familia (IPPF). Hacia 1969, la FPAK abrió su primera clínica modelo y empezó a contratar personal. Los avances fueron lentos: a lo largo de la década de los setentas, las actividades se centraron en la educación $y$ en alentar a las mujeres a utilizar anticonceptivos.

Para fines de esa década, un número creciente de mujeres empezó a utilizar métodos de planificación familiar; durante la década de los ochentas el papel y cobertura de los hospitales del Estado y las misiones aumentaron de manera considerable. La FPAK logró diversificar sus actividades y experimentar con varios elementos específicos de programas, por ejemplo, servicios para los jóvenes y los varones adultos; los programas distribución de base comunitaria (DBC); creación de directrices de información, educación y comunicación (IEC); mejoramiento de la calidad de los servicios, y expansión de los programas de salud reproductiva. Estas actividades, así como la posterior introducción del COPE, se emprendieron a menudo con el apoyo del Ministerio de Salud de Kenia. "La FPAK es independiente pero se le ve como una especie de rama del Ministerio de Salud", afirma Jane Asila, instructor principal de la División de Salud Familiar del MSK. "Si deseamos explorar nuevas áreas la FPAK está siempre dispuesta a efectuar pruebas piloto por nosotros, para probar cosas nuevas y evaluar directrices novedosas."

La FPAK desarrolla actualmente sus actividades con un presupuesto anual de más de 300 millones de chelines kenianos (\$5 millones de dólares estadounidenses) y 250 miembros de personal asalariado de tiempo completo (quienes en su mayoría respaldan el programa de DBC en el campo; 100 trabajan en las clínicas). La FPAK tiene un programa variado; sin embargo, más de 50 por ciento de su presupuesto se reserva para los servicios de planificación familiar. La organización mantiene 14 clínicas de salud reproductiva que ofrecen servicios de planificación familiar, Papanicolaou, pruebas de embarazo, examen de senos y revisión (incluso pruebas de laboratorio) y tratamiento de enfermedades de transmisión sexual. Además, tres clinicas nuevas financiadas por el programa Visión 2000 de la IPPF ofrecen servicios exclusivos para varones. FPAK ofrece servicios de PAC a través de una red de más de mil voluntarios que trabajan en 21 establecimientos en todo el pais y gestiona dos centros de orientación juvenil. Una iniciativa reciente es el proyecto de género

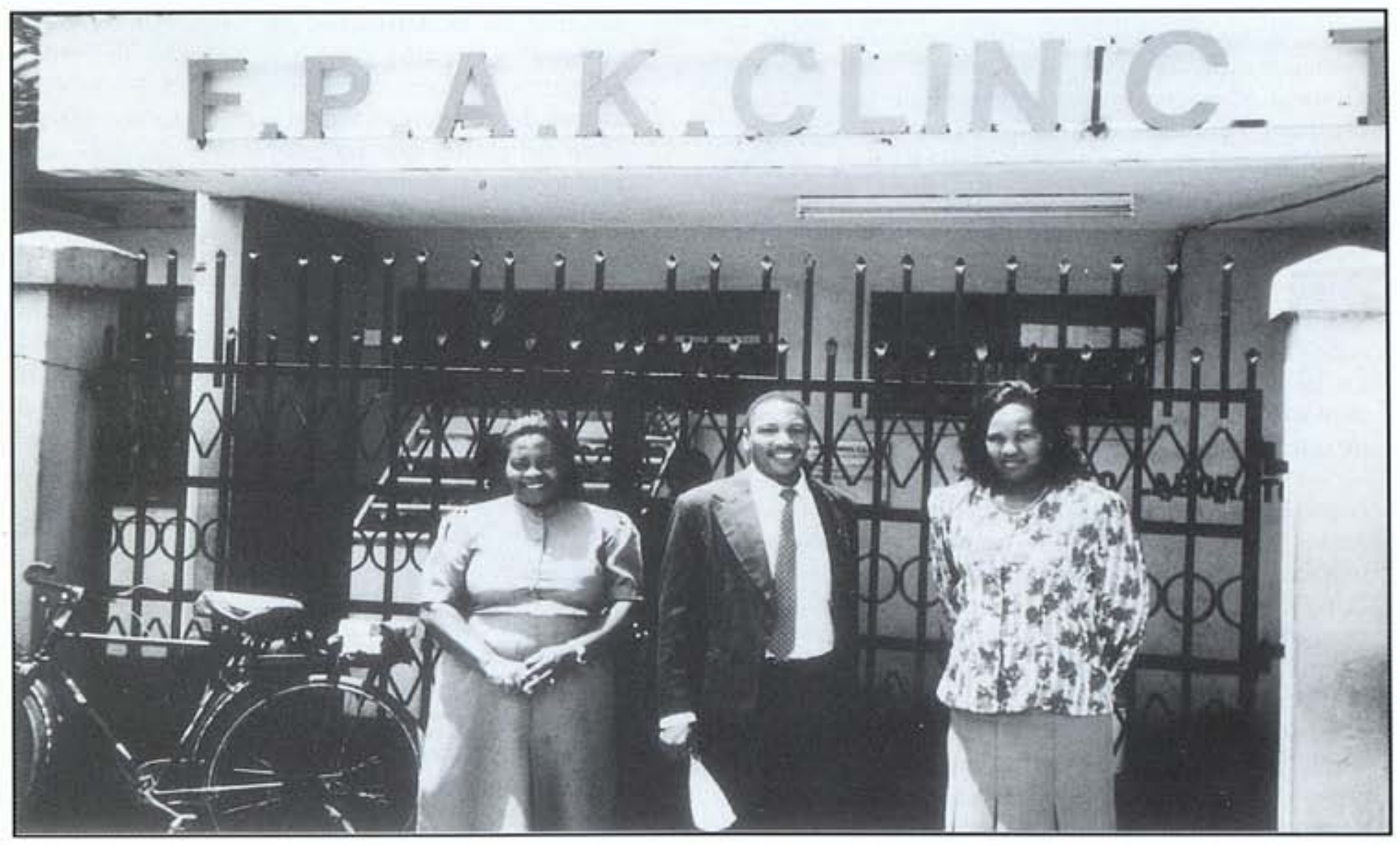


a través del cual la FPAK, junto con Plan Internacional, está creando un programa de promoción para tratar temas tales como el matrimonio precoz y la mutilación genital femenina. Asimismo, la organización ha iniciado esfuerzos para crear un programa de atención post-aborto.

Durante la década de 1980, FPAK se alió con la organización no gubernamental AVSC Internacional -con sede en Nueva York-, para introducir innovaciones clínicas como la minilaparotomía con anestesia local. Con el tiempo FPAK se convirtió en un centro de formación clínica fundamental para la introducción de tecnologías nuevas, incluso los implantes anticonceptivos Norplant ${ }^{\circ}$. Sin embargo, las posteriores evaluaciones que la FPAK y AVSC Internacional realizaron sobre la atención ofrecida en el suministro de estas tecnologias, revelaron defíciencias tanto en los aspectos técnicos como personales de la atención. Esta evaluación ocurrió durante un momento en el que los criterios para el éxito del programa empezaban a definirse respecto a qué recibian en realidad los usuarios, más que en cuanto a la gama ofrecida de tecnologias. Evidentemente, habia la necesidad tanto de adiestrar a un mayor número de médicos generales como de ampliar el contenido de la formación misma, para incluir algo más que habilidades técnicas.

\section{Primeros Intentos por Mejorar la Calidad de la Atención}

"Creo que empezamos a hablar de calidad de la atención a mediados de la década de 1980", afirma Godwin Mzenge, director ejecutivo de la FPAK en Nairobi. Y agrega: Siempre habiamos estado orgullosos de la alta calidad de los servicios que prestábamos, pero nos dimos cuenta de que habia lagunas, no estábamos cabalmente preparados para tratar la epidemia de VIH y las cuestiones de inocuidad concomitantes; no teníamos normas de atención definidas; no contábamos con la suficiente orientación sobre la calidad; los usuarios esperaban mucho tiempo en las clínicas; nos dimos cuenta de que había demasiadas barreras médicas. Estábamos conscientes de que debiamos hacer algo, pero... ¿qué?

Uno de los primeros intentos por mejorar la calidad consistió en observar los tiempos de espera de los usuarios, aplicando un análisis de flujos de usuarios (AFU) en cinco clínicas de la FPAK. "Utilizamos el programa de cómputo de los Centros para el Control de Enfermedades (CCE) y, en efecto, identificamos los tiempos de espera como un problema importante", dice el doctor Isaac Achwal, director principal de Programas de la FPAK. "Sin embargo, como no contábamos con una computadora y, dada la complejidad del proceso, no pudimos repetir el AFU a mayor escala y tuvimos que abandonarlo. Teniamos que hacer algo más sencillo que el personal pudiera utilizar por sí mismo de manera progresiva".

En 1986, la FPAK organizó su primera reunión para mejorar la calidad para funcionarios de programa y de prestadores de servicios, pero el resultado no fue nada alentador. "Tomamos la decisión de considerar por primera vez nuestros problemas pero lo único que logramos es que todo el mundo le echara la culpa a los demás. Los supervisores culparon a las clínicas, las clínicas al departamento de suministros, el departamento de suministros a los directores de área, los directores de área a los médicos, y los médicos a las enfermeras. Todo el mundo tenía historias de alguien más y nadie tenía nada constructivo que decir ni entendia las limitaciones de los demás". Buscar a alguien a quién responsabilizar provocó que el personal se pusiera a la defensiva y pronto se hizo evidente que había una falta de confianza fundamental entre ellos; las personas temían tomar decisiones o asumir responsabilidades.

Otros intentos primerizos por encontrar una solución giraron en torno a la creación de directrices y normas básicas para la práctica clínica: elaborar planes de estudio para la orientación individual, formación de personal y preparación de listas de verificación para la supervisión. En esta época, la FPAK adoptó también un lema que decia: "El usuario siempre tiene la razón", pero el esfuerzo seguía siendo retórico y mecánico. Las reuniones anuales de la FPAK se centraban debidamente en la calidad mas, a pesar del entusiasmo entre el personal, nadie se ponia de acuerdo en la definición de "mejoramiento de la calidad" y no surgió ningún sentido de esfuerzo colectivo. El doctor Achwal y sus colegas se dieron cuenta de que debian volver a formular su enfoque e idear un marco que no inhibiera el análisis de los problemas. El doctor Achwal recuerda ahora que, en realidad, estaban "tratando de legislar la calidad".

"En un principio, ni siquiera se invitó a los directores de área (supervisores regionales) a las reuniones anuales de planificación", afirma Godwin Mzenge. "Se sentian excluidos y no respaldaban los cambios que intentaba hacer el personal clínico. Además, la idea de concentrar todo en el usuario ignoraba las necesidades de los prestadores; de hecho se siguió 'culpando' a los prestadores por las insuficiencias del programa." Esta división fue acicateada sin querer por la decisión de aprovechar personal de las clínicas "buenas" para ayudar a otras clínicas. Fue en este momento cuando la FPAK tomó conciencia de que las personas no eran el problema. En realidad, el problema era que trabajaban en un sistema que no brindaba apoyo, que estaba en exceso centralizado y, en ocasiones, resultaba punitivo. Esto creaba una atmósfera en la que los temas no podian debatirse con franqueza ni era viable proponer cambios de gran inventiva. 


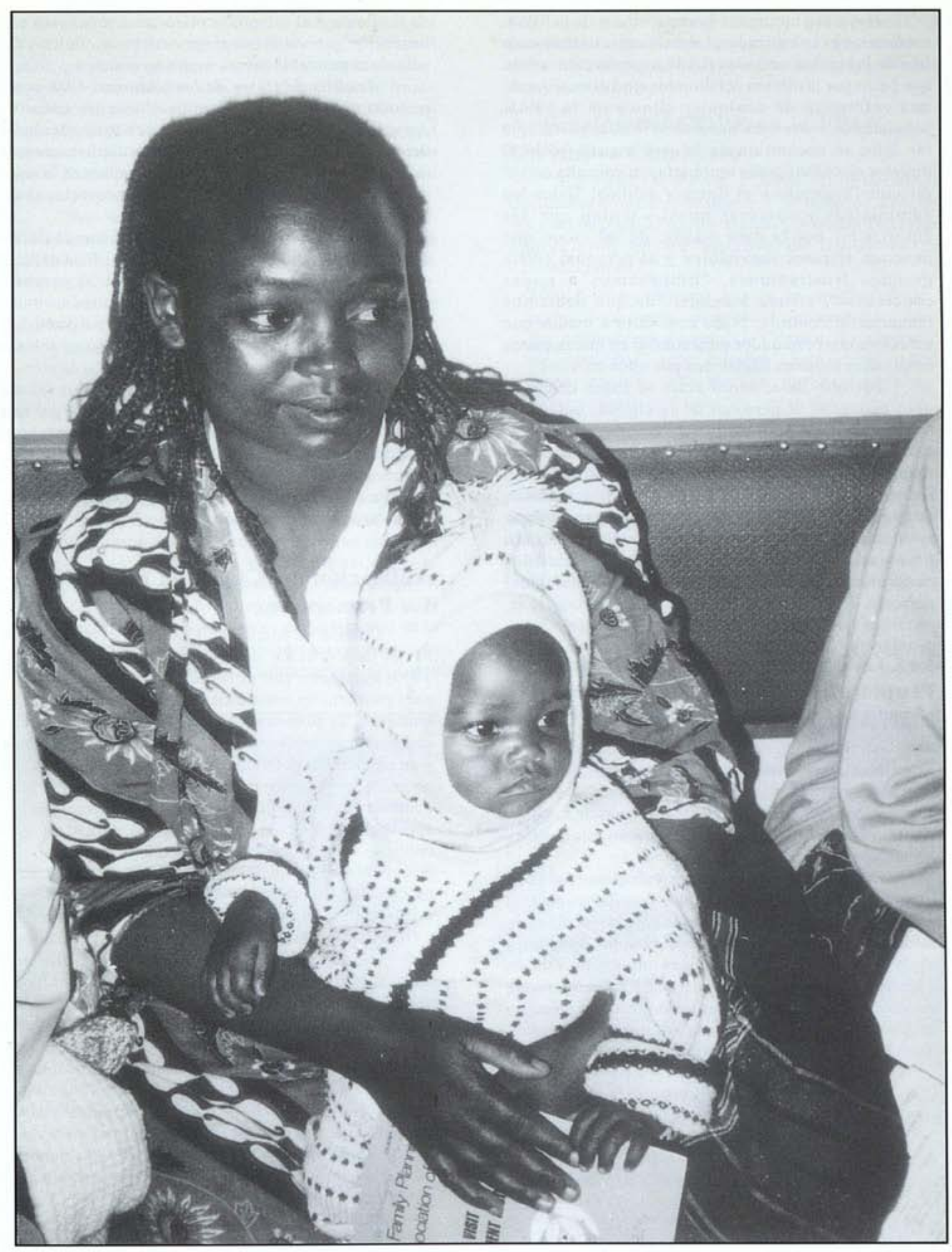

플 
Hasta ese momento, las actividades de la FPAK estaban muy centralizadas. Literalmente, todas y cada una de las cartas enviadas por la organización tenian que pasar por la oficina del director ejecutivo. Cuando una enfermera de cualquier clínica de la FPAK solicitaba licencia para ausentarse -sin importar qué tan lejos se encontrara de la casa matriz- ¡sólo el director ejecutivo podia aprobarla, en consulta con el director financiero y el director médico! Todos los suministros y compras nuevos tenian que ser autorizados por la casa matriz, de tal modo que ocurrian retrasos inevitables y el personal sufria grandes frustraciones. "Empezamos a tomar conciencia", afirma Mzenge, "de que debiamos renunciar al control... Nada cambiaria a menos que estuviéramos preparados para confiar en que nuestros empleados tomaran decisiones por ellos mismos".

Por otro lado, nunca antes se había delegado gran autoridad al personal de la clínica, nunca los habian alentado para evaluarse a sí mismos y a la calidad de los servicios, y ellos jamás habian estado dispuestos a admitir sus errores por temor a las represalias. Los mandos directivos se dieron cuenta de que la delegación de responsabilidades para mejorar la calidad implicaba más que la descentralización, pues no sería viable de no crearse paralelamente las condiciones para la realización del potencial del personal de la clínica.

\section{El COPE: Una Técnica de Evaluación Propia para Mejorar los Servicios de Planificación Familiar}

Alrededor de esta época, AVSC Internacional experimentaba con una nueva herramienta llamada COPE, concebida para ayudar al personal a evaluar sus propios servicios y a identificar formas de mejorar. La técnica COPE consta de cuatro elementos principales.

Evaluación propia. Esta se realiza ante todo con la ayuda de guias.' El personal las utiliza para a) evaluar y definir su necesidad particular de información, capacitación, aportes sobre gestión y supervisión, suministros y un buen entorno de trabajo; b) para evaluar si los servicios tratan los derechos que sus usuarios tienen a la información, acceso, elección de método, inocuidad, intimidad, confidencialidad, dignidad, comodidad, expresión y continuidad.

Entrevistas a los usuarios. El personal entrevista a 10 usuarios de clínicas y les piden su opinión sobre los servicios y qué sugerencias tienen para hacer mejoras. Por lo general, los entrevistados se seleccionan entre usuarios que esperan servicios o, en ocasiones, se aborda a mujeres justo antes de salir

1. En un principio recibieron el nombre de listas de verificación; en 1993 se modificaron y se les dio el nuevo nombre de guias. de la clínica. Las preguntas planteadas se refieren a la impresión general sobre el servicio en la clínica y no sólo su experiencia en esa visita en concreto.

Análisis de flujos de los usuarios. Este es un método para hacer un seguimiento de los usuarios durante su visita a la clinica. Permite a los prestadores determinar cuánto tiempo pasan los usuarios en espera de los servicios, dónde ocurren los cuellos de botella y si el tiempo del personal pudiera aprovecharse de manera más eficiente.

El plan de acción. Este es un resumen de las otras tres herramientas de evaluación del COPE a manera de plan por escrito. Creado por el personal durante el último dia del COPE, enumera las acciones que habrán de emprenderse para resolver los problemas identificados, las personas responsables y las fechas previstas para la realización.

En su origen, el COPE fue principalmente un conjunto de listas de verificación. Sin embargo, con el paso del tiempo se ha convertido en un proceso para el cambio y para lograr mejoras de la calidad. La experiencia de la FPAK en la aplicación del COPE, descrita a continuación, fue un importante factor que contribuyó a esa evolución.

\section{Aplicación del COPE en la FPAK: La Primera Vez}

Cuando se enteró del COPE, el personal de la FPAK estaba ávido de probarlo. Así, entre 1987 y 1990, trabajaron con el MSK y AVSC Internacional para probarlo en unos cuantos establecimientos. Sin embargo, la primera versión del COPE demostró concentrarse demasiado en las herramientas mismas y en servicios especificos de la clínica, en lugar de las necesidades del personal o del usuario. Pronto se hizo evidente que para ser efectivas, las herramientas debian aprovecharse como instrumento de apertura al diálogo continuo sobre la calidad de la atención, para reasignar la capacidad de decisión entre el personal y para modificar las actitudes del prestador hacia los usuarios. Por ejemplo, en un principio todos los informes del COPE debian enviarse a la casa matriz y, dado que todo seguia pasando por la oficina del director ejecutivo, la llegada de esta acumulación de enormes problemas causaba gran consternación a los mandos directivos de la FPAK. "El personal de la casa matriz se preguntaba por qué las clínicas tenian tantos problemas al mismo tiempo", afirma el doctor Achwal. "El personal de la casa matriz enviaba cartas a la clinica y exigia una explicación, incluso enviaba cartas en las que advertía que estos problemas debian resolverse de inmediato. Era evidente que el asi llamado ejercicio de evaluación propia se estaba aplicando de manera punitiva".

Cuando se hizo patente que este enfoque había fracasado, la FPAK intentó entonces utilizar a personal 
de una clínica para llevar a cabo la aplicación del COPE en otra. "Esto tampoco funcionó; el personal sentia que se le espiaba, se le dividia y se le utilizaba", recuerda Jane Magu, recepcionista de la Clinica Phoenix House. "Lo llevamos a cabo el 2 de enero. Descubrimos tantos problemas. Demostraba que nuestro trabajo era atroz, muy ineficiente... ¡Pensamos que lo habian aplicado para obtener evidencia de que debían despedirnos!"

"Nos sentiamos muy amenazados", concuerda Alice Ngugi, enfermera de la clínica, "en especial dado que lo hicimos el 2 de enero. Pensamos que era muy poco propicio. ¡Qué mal comienzo de año!"

Junto con el COPE, la FPAK introdujo listas de verificación para la inspección y cajas de sugerencias de los usuarios. Durante las visitas de inspección, el personal y los supervisores analizaban los hallazgos de los segundos, los resultados del COPE y las quejas de los usuarios. Pero, a pesar de lo mucho que los supervisores trataban de ser positivos, los análisis seguian sugiriendo que el personal no cumplia.

"El problema era que se seguía considerando al personal como el problema, en lugar de la solución", afirma Joseph Dwyer, director regional para África de AVSC Internacional. "Debía concebirse un nuevo enfoque que creara las condiciones para la participación plena del personal y lo respaldara en lugar de culparlo, lo que suponia un mayor conocimiento del proceso para el mejoramiento de la calidad por parte de los supervisores y el personal de la casa matriz, que buscara subrayar los aspectos positivos y no los negativos, y que realzara la propiedad de las herramientas para el mejoramiento de la calidad en manos del establecimiento, no de los supervisores".

\section{Aplicación del COPE en la FPAK: Un Nuevo Comienzo}

En 1993, la FPAK y AVSC Internacional decidieron comenzar de nuevo. ${ }^{2}$ Se tomaron a pecho los comentarios de Carlos Huezo y Soledad Diaz que aparecieron en un articulo de Advances in Contraception. ${ }^{3}$

Una estrategia para lograr la calidad de la atención no puede ser realista sin reconocer que los prestadores de servicios tienen sus propias necesidades que pueden resumirse asi: capacitación, información, infraestructura, suministros, orientación, respaldo, respeto, aliento, respuesta y estilo personal.

El suyo fue un mensaje importante. Era evidente que las necesidades del personal no se estaban explorando a fondo y no habia una estructura supervisora que lo estimulara o apoyara; el personal no disfrutaba del mejor de los entornos de trabajo posibles. En otras palabras, se esperaba que el personal brindara a los usuarios lo que no tenia para si mismos.

Hacia 1993, el interés internacional empezó a centrarse en la noción de los derechos a servicios de calidad que tienen los usuarios. El cartel de la IPPF

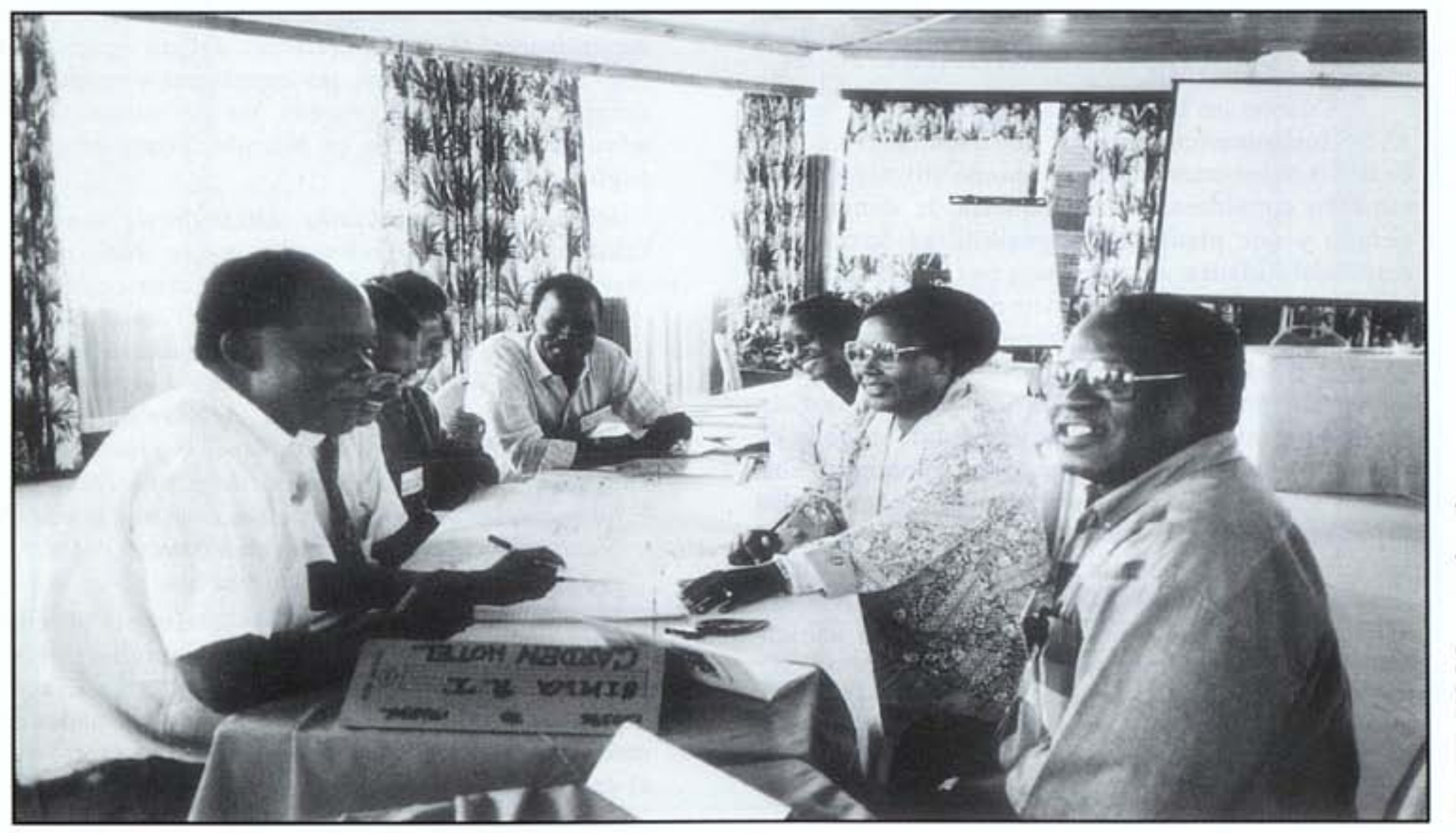


que define los derechos de los usuarios se hizo circular ampliamente y comenzaba a aparecer en las paredes de clinicas en todo el mundo, incluso de Kenia. ${ }^{4}$ Casi de inmediato, el personal de la FPAK se identificó con estas ideas con respecto a su propia situación. Empezaron a considerar a sus usuarios como "clientes" que se presentaban en la clínica para ser servidos. Explica Grace Wambwa de AVSC Internacional: $"$ ¿Cómo podia (el personal) proporcionar información a los usuarios sobre un nuevo método sobre el cual nunca se les había puesto al día? ¿Cómo podíamos esperar que prestaran servicios seguros, desinfectaran instrumentos y cosas similares, si nunca se les habia explicado la necesidad y no se les daban los liquidos para la descontaminación y esterilización?"

Como resultado de este nuevo enfoque AVSC Internacional y sus socios kenianos ordenaron de nuevo las listas de verificación para la evaluación. Antes se habian organizado de manera funcional en torno a las distintas áreas de prestación de servicios; en ese entonces se volvieron a formular en diez guias, siete dedicadas a los derechos de los usuarios y tres a las necesidades de los prestadores. Las guias de evaluación própia también se elaboraron en forma modular para que pudieran seleccionarse las más adecuadas para su uso, su sencillez les permitía su empleo rutinario y económico.

En ese momento, también se modificó la manera de aplicar el COPE, capacitando al personal para que efectuara la aplicación por sí mismo. La realización de un ejercicio del COPE exige que el personal se divida en grupos; cada uno de los cuales asume la responsabilidad de una de las guías y elabora un anteproyecto de plan de acción que se presenta ante el pleno para su análisis.

Cuando las herramientas mismas se revisaron, AVSC Internacional descubrió que mientras el análisis de flujos de usuarios se percibia como útil, el personal también consideraba que requería de demasiado tiempo y que planteaba la posibilidad de asignar responsabilidades a individuos por los problemas identificados. "En un principio no nos agradó el AFU", afirma Rebecca Isiche, enfermera y partera de la Clínica Eastleigh. "Era demasiado personal. La aplicación muestra el contacto de un prestador de servicios particular con los usuarios durante todo el dia. Lo que no muestra es que cuando uno no estaba con el usuario, esterilizaba instrumentos, ordenaba expedientes, o hacia otras labores importantes".

Tampoco mejoró la calidad de las consultas: "Nos preocupaba demasiado apurar la entrada y salida de los usuarios para que no pareciera que habian esperado demasiado rato". Por último AVSC Internacional sugirió que se diera menos énfasis al AFU y se aplicara sólo cuando se percibieran los tiempos de espera (u otros cuellos de botella graves) como un problema. Sin embargo, si en una clínica se toma la decisión de aplicar el análisis de flujos de usuarios, también se habrá hecho de manera amable; ahora los datos pueden calcularse localmente como parte del ejercicio de COPE, y luego presentarse al pleno junto con la demás información.

Muy probablemente, las herramientas de la aplicación seguirán cambiando: ya hoy se dispone de guias complementarias que tratan complicaciones del aborto, temas de sala de maternidad, exámenes de senos, Papanicolaou e infecciones del tracto reproductivo. Kalimi Mworia, director regional adjunto de la IPPF y antiguo director ejecutivo de la FPAK resume la idoneidad del COPE: "El COPE es, en verdad, una invención africana moldeada por la gente a la vanguardia de los temas de prestación de servicios. Precisamente por ello funciona". No obstante, el proceso de ejecución del COPE ha dejado claro para la FPAK y AVSC Internacional que las herramientas no son suficientes por si solas. Sin un cambio de actitud y un sistema sustentador dentro del cual aprovecharlas, las herramientas serian inútiles. Asi, el COPE se ha convertido en un proceso que incluye hoy dia otros muchos elementos importantes.

\section{Un Nuevo Enfoque en La Supervisión}

Entre otras cosas, el proceso del COPE reveló problemas fundamentales en la forma de configurar los papeles de los supervisores. Joseph Dwyer de AVSC Internacional observa: "En Kenia, los servicios se estaban ampliando a tal velocidad que el mejoramiento de la calidad y la garantía de ésta no podian ser la esfera de acción de unos cuantos supervisores". Los supervisores debían aprender a convertirse en los guias, los impulsores y en quienes dotaran de ánimo al proceso, no sus custodios. El administrador de área en Nairobi, Njagi Muchiri, explica:

Mi papel ha cambiado. Disfruto de mayor
autonomia que antes y ello me ha dado más
confianza para respaldar a las clinicas en lugar
de fiscalizarlas. Solia ir a las clinicas con el único
objetivo de encontrar fallas, pero ahora voy a
apoyarlas. Mi trabajo es asegurarme que tengan
los suministros necesarios, ayudarlas a dar
mantenimiento al equipo, resolver problemas,
ayudar en la conservación de expedientes y
formar al personal en el trabajo, en donde pueda.
Siento que me aprecian más en mi nuevo papel y
eso hace más gratificante mi trabajo.

Aunque siguen apareciendo problemas conforme vuelve a definirse la relación entre el prestador y el supervisor, en última instancia, la mayoria de los supervisores siente que el papel de mediador vale más la pena y es más satisfactorio que el de inspector. 


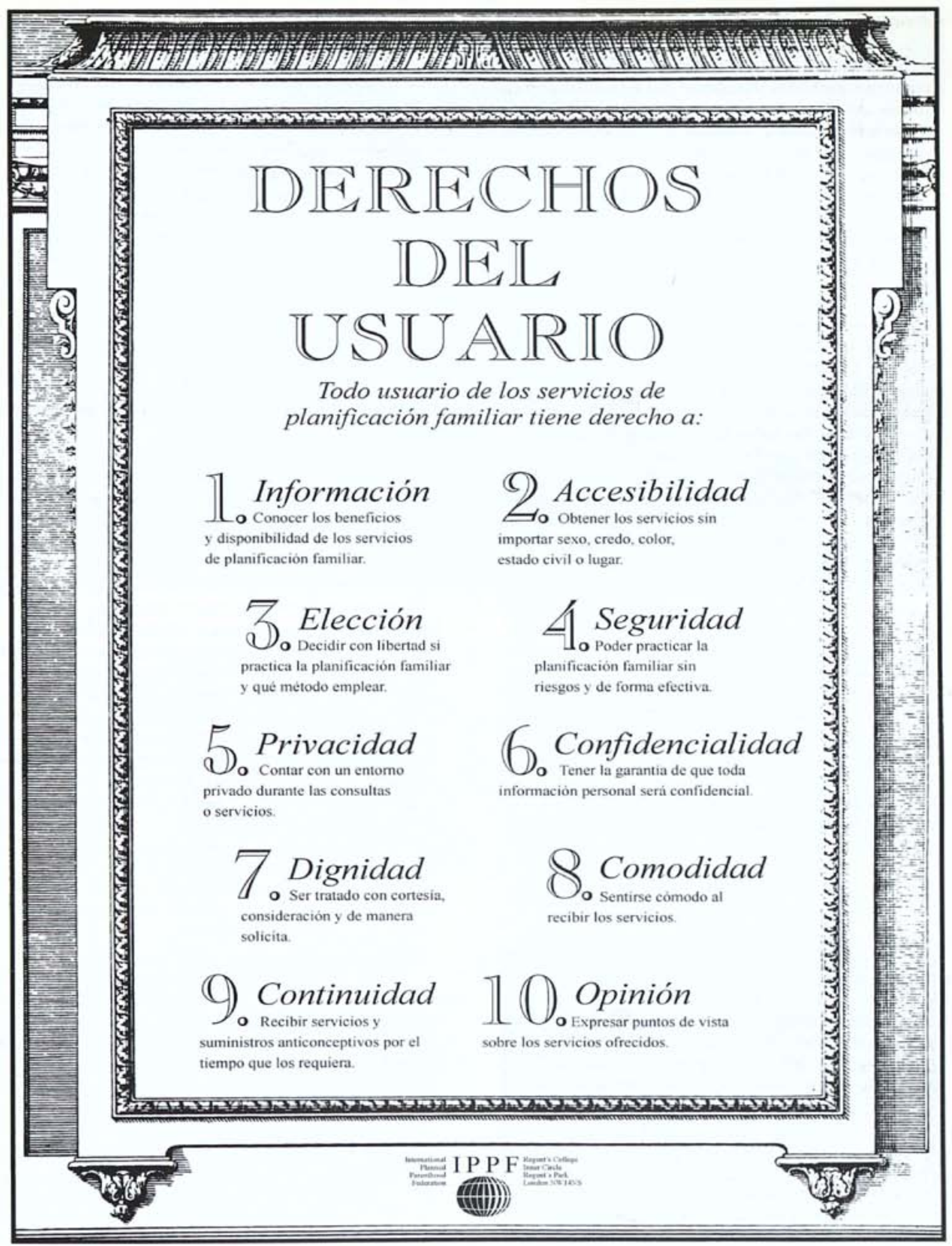




\section{Formación en el trabajo}

$\mathrm{Al}$ aplicar el COPE, los prestadores identificaron como un problema frecuente los bajos niveles de formación. Hasta ese momento, como la mayor parte de las instituciones de Kenia, la FPAK habia recurrido a la aplicación periódica de programas de capacitación formales y centralizados, llevados a cabo en establecimientos externos. Pero actualmente la FPAK está convencida de que, en la mayoria de los casos, el adiestramiento en el trabajo es un medio más rápido, eficaz y menos costoso para mejorar las capacidades del prestador. Nzioka Kingola, director de área de Nyery observa: "Nos hemos dado cuenta de que la formación no significa obtener un certificado, sino adquirir conocimientos y capacidades para realizar un trabajo. La mayor parte de esos conocimientos y capacidades existen aquí mismo simplemente tenemos que aprender a sacarles provecho".

Lo más alentador ha sido cómo los miembros del personal de las clínicas se han convertido por sí mismos tanto en alumnos como en formadores ávidos. En la Clínica Nyery de la FPAK, el personal de enfermeria (respaldado por un supervisor con una sólida formación) se ha adiestrado en tecnología anticonceptiva -incluso métodos permanentes- y en asesoria, prevención de infecciones, gestión de los elementos necesarios y el mantenimiento de registros. Sacando partido de la información actualizada, organizaron por si mismas sesiones de formación y el único gasto en el que incurrieron fue en el de papel. En la Clinica Phoenix House, el personal se ha orientado mutuamente respecto a todos los métodos de planificación familiar disponible. Se turnan en la lectura de publicaciones sobre un método particular y en la presentación de sus hallazgos a los demás. La FPAK ha facilitado este proceso formando al personal en técnicas educativas y estableciendo una biblioteca en cada establecimiento.

Otro beneficio de este enfoque es que ha eliminado las jerarquias internas. En la Clínica Ribeiro,

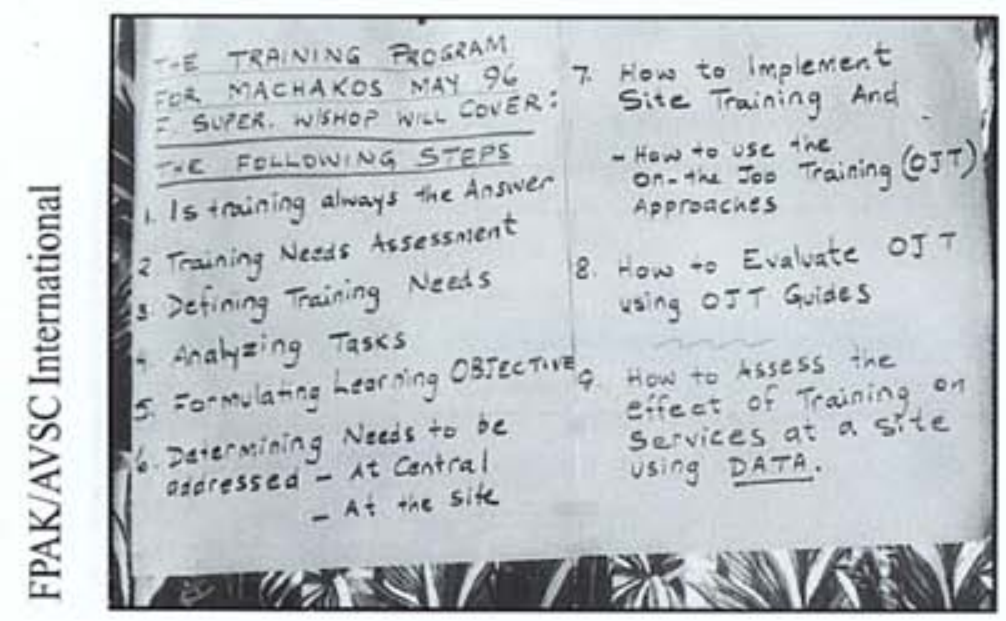

la enfermera principal instruyó al afanador y mensajero en prevención de infecciones, le mostró como limpiar debidamente la clínica y las autoclaves, lo orientó en los métodos de planificación familiar masculinos y lo alentó a conversar con los usuarios. "Creía que mi trabajo seria sólo limpiar, pero ahora me han dado la confianza para realizar toda suerte de tareas", afirma Francis Ndungu. En realidad, Francis ha adquirido tanta confianza que él mísmo ha dirigido algunas de las sesiones de formación, instruyendo a los demás sobre prevención de infecciones, cómo utilizar la autoclave, y en la eliminación correcta de desperdicios. Aunque en Kenia la incorporación de directrices en el trabajo tardará mucho en aceptarse -para que se legitimen en el país hace falta más apoyo del MSK ( $\mathrm{y}$ de donadores)-, la FPAK está convencida de que está en el rumbo correcto.

\section{Cesión de Control a las Clínicas}

Quizá la contribución más importante de la casa matriz de la FPAK a todo el proceso COPE haya sido la descentralización del sistema de toma de decisiones. El personal puede comprar equipo en su localidad cuando lo necesite, en lugar de pedir permiso a la casa matriz. "Todavia tengo que rendir cuentas", dice Ednah Namiti, "pero puedo decidir con mayor libertad cuánto dinero gastar. Es mucho mejor; siento que tienen una mayor confianza en que haré lo pertinente".

"La descentralización fue un proceso gradual pero el personal empezó a trabajar unido en equipos justo cuando la gente aprendió a dejar de fiscalizar a todo el mundo", señala Kalimi Mworia. "Debiamos tener la confianza para ceder, para modificar todo un esquema mental de control y una sensación de que los de aquí, en la casa matriz, éramos los únicos que sabiamos algo. Teníamos que dejarlos gestionar a ellos mismos el proceso de cambio y no obligarlos. Nunca pensé que podríamos hacer esto en África, pero lo logramos". Con este cambio en el lugar del control, los prestadores de servicios no sólo empezaron a sentirse más cómodos con las directrices para el mejoramiento de la calidad, sino que empezaron a sentirse más valorados por la organización.

La información generada por la aplicación del COPE es sensible. Al reconocer esto, uno de los principales cambios que hizo la FPAK fue dejar de insistir en que los informes del COPE llegaran a la casa matriz para su revisión. Ahora estos hallazgos son propiedad del personal de la clínica, quien también analiza las sugerencias del usuario con su supervisor y se les ha dado mayor responsabilidad para emprender acciones cuyo objetivo es resolver los problemas que identifiquen.

Actualmente, los prestadores de la FPAK en todos los establecimientos efectúan reuniones para el mejoramiento de calidad, incluso realizan una 


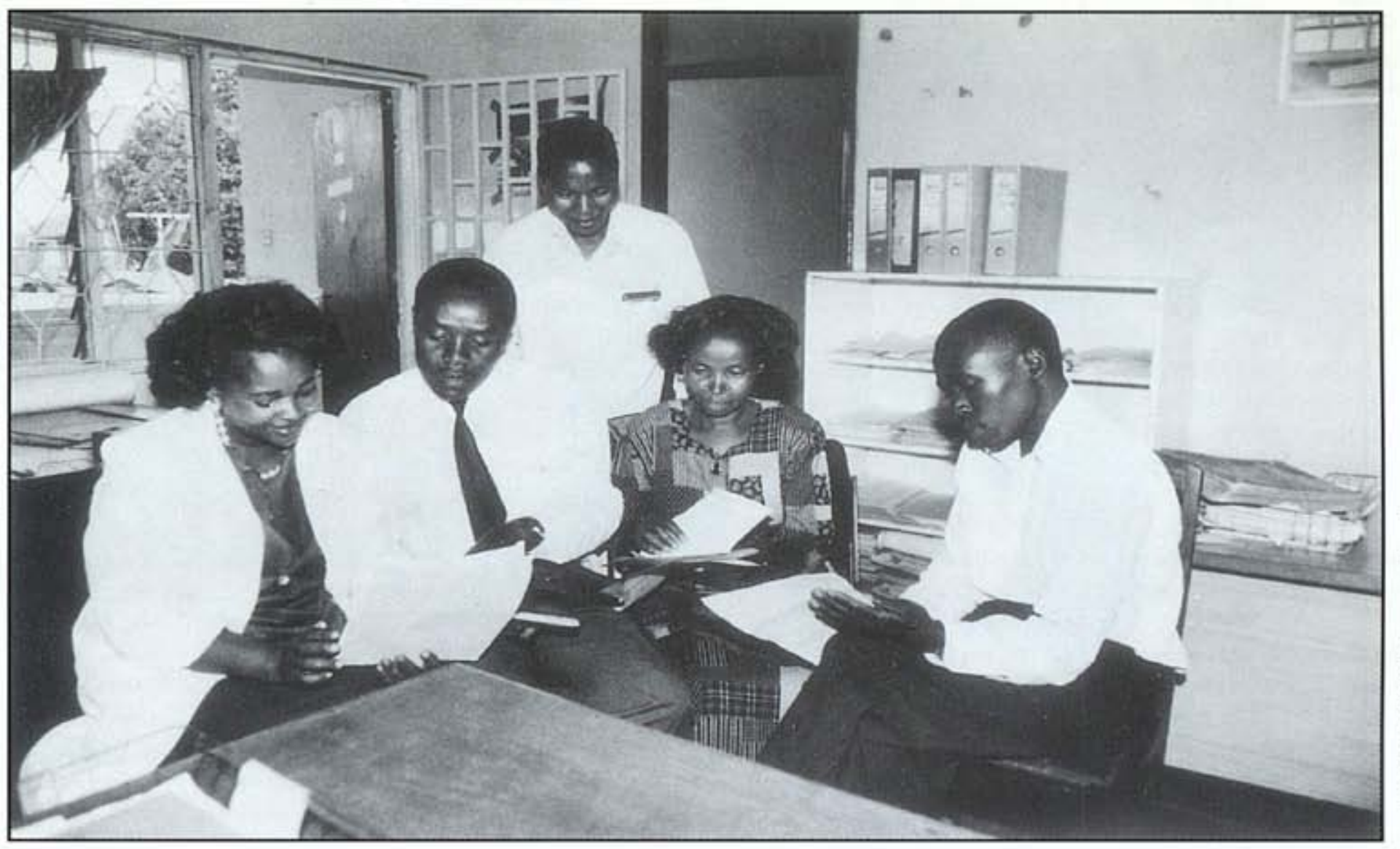

aplicación del COPE, cada tres meses. Disfrutan al aplicar el COPE porque les pertenece. "Desde luego, siguen apareciendo ciertas cosas en nuestra lista de 'deberes' cada trimestre: por ejemplo, le insistimos a la casa matriz que le dé más promoción a nuestra clinica", dice Rebecca Isiche, enfermera de la Clinica Phoenix House de la FPAK. "Eso es frustrante, ipero debieron haber visto la larga lista de problemas que teniamos en un principio y cuántos hemos solucionado!"

\section{Ahora Todos Trabajamos Unidos como Equipo}

La aplicación del COPE alienta al personal a asistir y participar en las sesiones de solución de problemas. Para muchos, esta es la primera vez que han tenido comunicación directa con los altos mandos. "El personal se siente privilegiado y emocionado por participar", afirma Jane Asila del Ministerio de Salud. "Como nunca nos habiamos comunicado y, por ello, no habiamos atendido las quejas de los usuarios, simplemente seguiamos igual. Aun si pensábamos que algo estaba mal, nunca se nos animaba a expresar nuestro punto de vista", afirma Florence Githera de la Clinica Eastleigh. Ella misma dice:

" Estábamos perdiendo usuarios y ni siquiera intentábamos enterarnos por qué!" Y los mandos directivos, aunque al principio estaban un tanto renuentes, pronto se dieron cuenta de que hacer participar a todo el mundo facilita su trabajo. Mientras que en el pasado el personal habia sido dificil y poco cooperativo, ahora están empezando a planear y trabajar en conjunto. Dado que es su plan y no el de los jefes, las cosas empiezan a mejorar. ¡Luego se sienten capaces de respaldar el proceso!

En la Clinica Ribeiro, los miembros del personal se turnan en la gestión trimestral de aplicaciones del COPE, de modo que realmente se sienten involucrados y libres de expresar su opinión personal.

El enfoque del COPE alienta a todo el personal a asistir a reuniones; también anima la participación y el trabajo en equipo genuinos. "El enfoque del COPE ha modificado la cadena tradicional de órdenes", explica Jane Asila. Un hospital estatal había padecido durante años una escasez de agua que amenazaba la seguridad de los servicios. Después de una aplicación del COPE, las enfermeras organizaron una marcha por la ciudad en la que reunieron fondos suficientes para perforar un nuevo pozo. Ahora tienen agua suficiente para prestar servicios seguros y limpios, y se ha vuelto a abrir un quirófano cerrado durante varios años.

En la Clínica Thika, el trabajo en equipo ha mejorado de manera apreciable. "Antes de adoptar este nuevo enfoque, el estado de ánimo del personal estaba por los suelos", afirmó un miembro del personal. "Ni siquiera queriamos vernos las caras. Ahora nuestras 


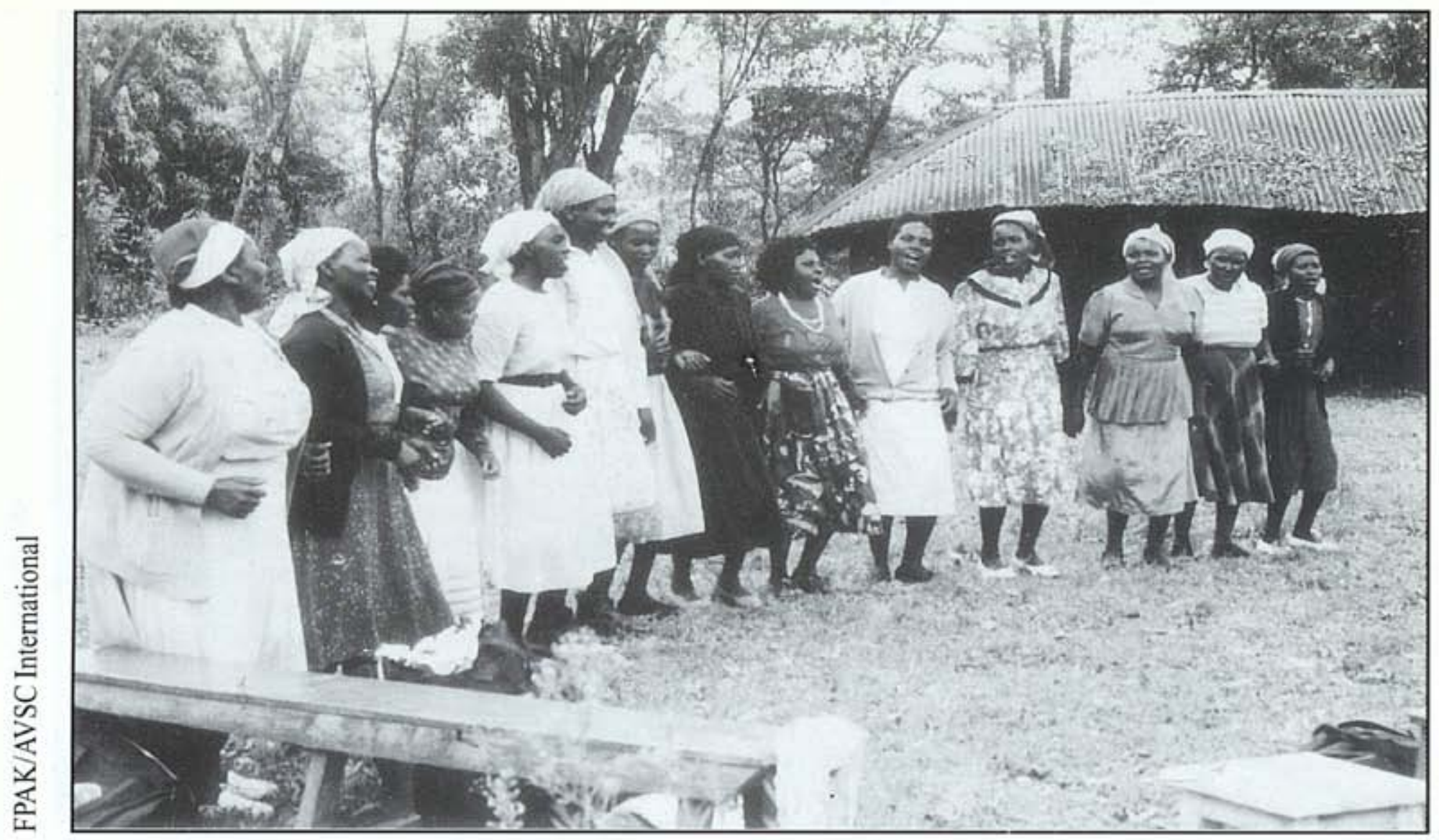

relaciones han mejorado tanto que si, por ejemplo, el encargado de los expedientes tiene una carga excesiva, otro miembro del personal vendrá al rescate". En un principio, el personal de la Clinica Eldoret se sorprendió cuando se presentó la sugerencia de que los choferes y el personal de limpieza se presentara en las reuniones del personal. "Nadie me habia preguntado nunca qué pensaba de los servicios y si tengo varias ideas", afirma un integrante del personal de limpieza. En la Clínica Nyeri, los jardineros y askaris (vigilantes nocturnos) también participan y se les ha dado orientación sobre planificación familiar. Todo el personal está de acuerdo en que esto es importante porque a menudo, quienes trabajan fuera, dan instrucciones a los usuarios. Ahora, incluso los fines de semana, los usuarios pueden asesorarse sobre cuándo acudir para obtener los servicios.

El proceso para el mejoramiento de la calidad parece haber contribuido también a que los miembros del personal se comprendan mutuamente y, a la larga, a sus usuarios. Como lo informa un miembro del personal de la Clinica Phoenix House:

Estamos conscientes de que nos necesitamos unos a otros y de que todos somos individuos con sentimientos y conductas que otros deben entender.. Todos debemos cooperar para obtener la confianza de los demás y ser amigables unos con otros. Estamos haciendo eso en Phoenix House, y ha modificado fundamentalmente la forma en que nos relacionamos con nuestros usuarios y el trato que les damos. ¿Cómo podemos ser corteses con los usuarios si, como prestadores, no somos corteses entre nosotros?

AVSC Internacional agrupó las áreas principales . de las necesidades de los prestadores, descritas primero por Huezo y Diaz, en tres categorias fundamentales dentro de las guías para la evaluación propia: 1) gestión y supervisión buenas; 2) información, formación y perfeccionamiento, y 3) suministros y buen entorno de trabajo. Como ya hemos visto, es evidente que están ocurriendo cambios positivos en las tres categorías. Del mismo modo, los derechos de los usuarios se han organizado en siete grupos principales: acceso a la información, elección, inocuidad, intimidad y confidencialidad, dignidad, opinión, comodidad y continuidad.

\section{Considerar a los Usuarios como "Clientes" y Hacerlos Participar en el Proceso}

Hacer participar a los usuarios en el proceso para el mejoramiento de la calidad ha sido una parte interesante y destacada del programa de la FPAK. Hoy 
dia, en las clínicas de la FPAK los prestadores hablan de su deseo de relacionarse mejor con los usuarios, de escuchar sus puntos de vista, y de crear el tipo de servicios que los usuarios recomendarian a sus amigos. "Creo que debemos empezar a considerar a los usuarios como si fueran nuestros clientes", dice Patricia Muiko, enfermera y partera de la Clinica Phoenix House.

La aplicación del COPE estimuló a la FPAK a revisar los esfuerzos previos por obtener retroalimentación de los usuarios. En el esquema anterior, se habian colocado cajas de sugerencias en las áreas de espera de todas las clínicas. Sin embargo, como informa el doctor Achwal: "No se informaba a los usuarios de las cajas de sugerencias, asi que no obteniamos muchas". Y añade, "Soliamos dejar la llave al supervisor, de tal modo que él controlaba las cosas. Las cajas se abrian cuando el supervisor visitaba la clínica y se utilizaban para criticar al personal".

Ahora, después del COPE, los usuarios no sólo están más conscientes de sus derechos sino que se les alienta a comentar los servicios de la clinica. Se ha elaborado un cuestionario que brinda la oportunidad de alabar, así como de criticar. Además, los miembros mismos del personal se han convertido en "propietarios" de esta información: jahora tienen la llave de la caja de sugerencias! Como consecuencia, el personal está ahora más atento a los comentarios de los usuarios y dispuesto a realizar los cambios necesarios.

Además de las sugerencias por escrito, como parte de las aplicaciones trimestrales del COPE, el personal hace entrevistas directas a los usuarios. Desde luego, los resultados de estas entrevistas suelen ser más positivos que negativos dado el sesgo de la cortesia, pero la aplicación cumple un objetivo importante. "Nuestros usuarios sienten que aquí son aceptados y que se les trata con respeto, y disfrutan que se les brinde la oportunidad de decir con libertad lo que piensan", afirma Ednah Namiti de Phoenix House. "Los usuarios nos dicen que han notado mejoras", añade otra enfermera. "Nos dan las gracias cuando reciben servicios seguros y rápidos; comentan sobre la limpieza y las agujas y jeringas nuevas. ¡Me inspira para hacer mejores cosas!"

El derecho del usuario a la información. Las clínicas de la FPAK siempre han estado a la vanguardia en el trabajo sobre información, educación y comunicación en Kenia. Pero en los años recientes, las mujeres kenianas desean más información. "Quieren conocer sus opciones; quieren saber sobre prácticas para prevenir infecciones", afirma una enfermera de Thika. "Ahora acuden aqui para preguntar cómo esterilizamos nuestros espejos antes de que accedan a que les hagamos un Papanicolaou. Las hemos instruido para que cuestionen y estén conscientes, y eso es bueno".
También ha aumentado el cúmulo de información proporcionado a los usuarios. Hoy dia, todas las clinicas de la FPAK dan pláticas sobre la revisión de los senos, la importancia del Papanicolaou, las infecciones de transmisión sexual, el VIH y el SIDA, asi como las pláticas comunes sobre planificación familiar. Las clinicas están bastante bien abastecidas con folletos y carteles que abarcan una amplia gama de temas, aunque debe instaurarse un mejor sistema de pedidos para IEC (similar al que existe para el demás equipo). Muchas clínicas muestran ahora las fechas de las próximas pláticas y se apegan al horario establecido. "De esa manera dice Ednah Namiti-si los usuarios desean información sobre cierto tema, pueden hacer arreglos sobre qué dia acudir para obtener los servicios". Los miembros del personal también se han dado cuenta que los usuarios suelen ser muy tímidos para plantear preguntas directas, de tal manera que los primeros deben iniciar el debate.

Los derechos del usuario a un servicio oportuno. Antes del COPE, la mayoria de las clínicas abria sólo los días hábiles, y cerraba a las 5:00 P.M., de tal modo que las mujeres trabajadoras no tenian acceso a los servicios. Cuando el personal de Nyeri entrevistó a los usuarios, descubrieron que muchos estaban en favor de que las clínicas abrieran los sábados, de allí que ahora laboran seis dias de la semana, y el personal ha pegado en toda la ciudad

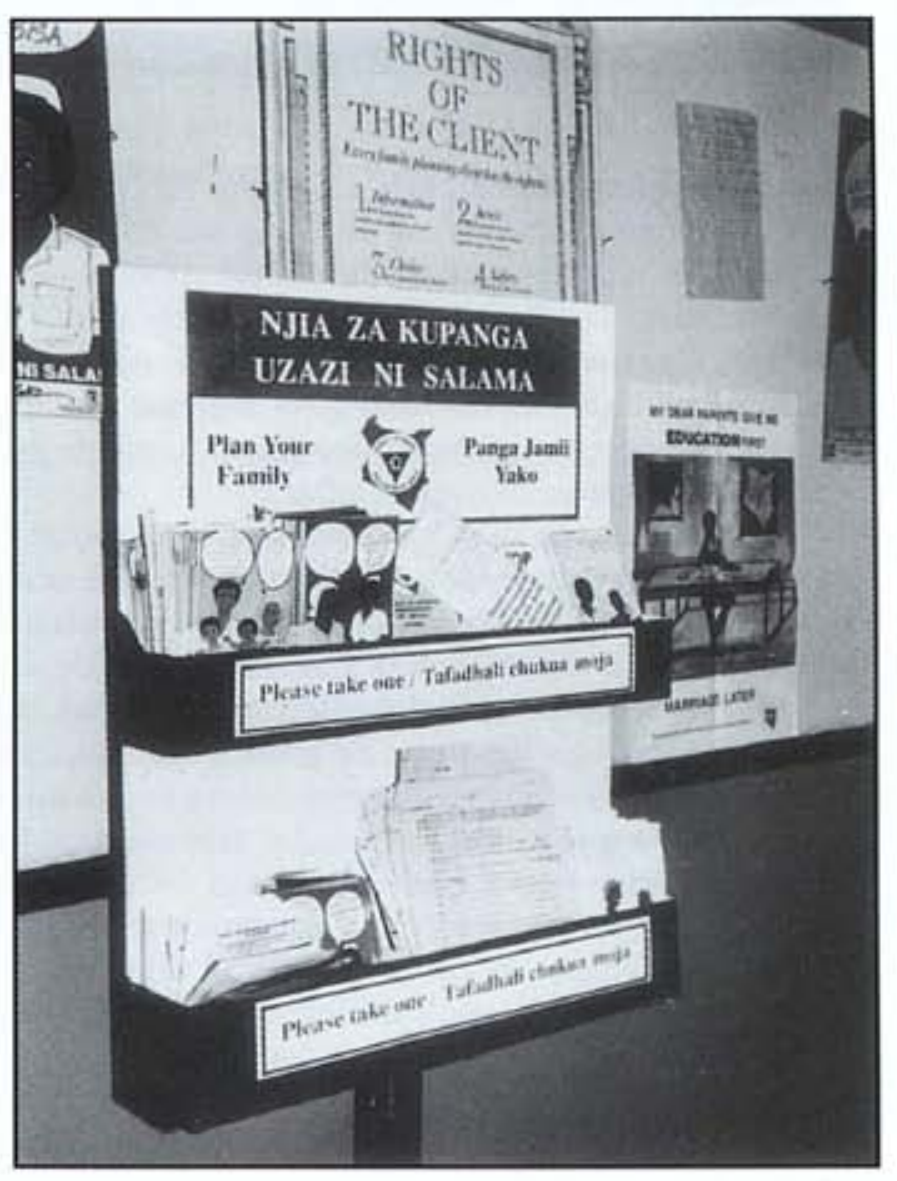


protocolos, de hecho, negaban ciertos servicios a las mujeres. Por ejemplo, hasta 1993, las clínicas de la FPAK exigian el consentimiento del cónyuge para realizar la ligadura de trompas, incluso cuando éste no era un requisito legal. El personal de la clínica decidió que, aunque era deseable el consentimiento conyugal, no debía ser obligatorio. "Así como a los prestadores se nos está dando la confianza para que tomemos decisiones, tenemos que confiar en nuestros usuarios, y creer que harán lo que les conviene". Como resultado de análisis estimulantes sobre los derechos individuales de las mujeres, también se alteraron las reglas con respecto a la prestación de servicios de planificación familiar a las mujeres solteras.

Desde hace poco, el acceso se ha visto afectado por otro factor: un aumento de las cuotas. Para algunas clínicas esto ha significado una reducción en el número de usuarios. Pero el tema de la justa fijación de los precios de los servicios, como todo lo demás en la FPAK, está abierto al debate. Algunos miembros del personal consideran que las tarifas son demasiado altas incluso si la calidad ofrecida es buena. El personal de la Clínica Nyeri, sin embargo, está en desacuerdo. Descubrieron que, aunque el número de usuarios disminuyó cuando subieron las cuotas, al comparar la buena calidad de los servicios de la clínica de la FPAK con lo que se ofrecía gratuitamente, los usuarios volvian. Pronto se habian dado cuenta de que los llamados servicios "gratuitos", en realidad, no lo eran en absoluto porque a menudo se pedia a los usuarios proporcionar elementos fundamentales como guantes $\mathrm{y}$ agujas. Aunque la mayoría del personal acepta que es inevitable cobrar cuotas realistas a los usuarios, sigue abierto el debate sobre la estructura de cuotas.

El derecho del usuario a elegir el método. La introducción de Norplant ${ }^{*}$ en Kenia, en 1992 -aunque coincidió con el proceso para el mejoramiento de la calidad que se encontraba en marcha en las clinicas de la FPAK-, ha significado una importante adición al conjunto de métodos disponible para los usuarios de la Asociación. Los retiros de Norplant ${ }^{\text {n }}$, sin embargo, han sido un tema de frecuente debate en las reuniones para el mejoramiento de la calidad. El personal de la Clinica Eastleigh, por ejemplo, estaba preocupado por el gran número de retiros solicitados. Después de un acalorado debate, se dieron cuenta de que debian asesorar a los usuarios de manera concienzuda sobre los efectos secundarios y la naturaleza a largo plazo del método. Cuando empezaron a hacer esto, disminuyó el número de solicitudes de retiros.

El personal de Phoenix House afirma que la formación los ha ayudado a brindar mejor asesoria a los usuarios acerca de todos los métodos. Admiten que solían dirigir a los usuarios a un método en particular, y sólo asesores con capacitación formal podian hablar con las mujeres sobre los métodos permanentes. En la Clinica Ribeiro, el personal se dio cuenta que no era amable con los usuarios y que deseaba cambiar de método, asi que ahora hace un esfuerzo consciente por reconocer los derechos de los usuarios en esta área.

El derecho del cliente a servicios seguros. EI derecho inalienable a la inocuidad del cliente se ha reforzado mediante la intensificación de los esfuerzos de seguridad contra infecciones. En vista de la epidemia del VIH y SIDA, miembros del personal admiten que, en el pasado, solian comprometer su propia salud y la de sus usuarios, en parte, porque no tenian el control del proceso de garantía de calidad. Como lo explica una enfermera: "Se nos decía que debíamos tener más cuidado y prevenir infecciones, pero no se nos mostraba cómo ni se nos entregaba el material adecuado".

Las guías del COPE subrayan que la prevención de infecciones es asunto de todo el mundo. AVSC Internacional ha proporcionado cuadros para la prevención de infecciones y ha auxiliado a la FPAK a organizar sesiones de actualización y orientación para todo su personal. Cuando los miembros del personal hicieron un compromiso con la seguridad, se apresuraron a solicitar guantes de uso pesado, cubos de descontaminación y liquidos esterilizadores. Estos cambios han producido una mejor inocuidad para los clientes. "Ni siquiera acostumbraba limpiar el sofá entre un usuario y otro", admite una enfermera. "Ahora me aseguro de tener todo listo y lo hago religiosamente. Otra enfermera señala que: "En la manera antigua de hacer las cosas, la afanadora, precisamente la persona que mejor debe saber cómo eliminar los desperdicios de manera adecuada, no recibía ninguna capacitación al respecto. Ahora se incluye a esa persona y, de hecho, a menudo se le elige para instruir a los demás".

Actualmente, los usuarios de la FPAK están más conscientes de la prevención de infecciones, y el personal fomenta esta conciencia. Alice Ngugi de

$$
\begin{aligned}
& \text { IF YOU LIKE OUR SERVICES TELL } \\
& \text { OTHERS } \\
& \text { IF YOU DO NOT LIKE OUR } \\
& \text { SERVICES TELL US. }
\end{aligned}
$$


Phoenix House recuerda: "Los usuarios solian recibir un trato $\tan$ malo que desconfiaban de nuestras motivaciones como prestadores de servicios. Creo que es esencial ser honesto con el usuario; realmente desea estar mejor informado. Si proporcionamos servicios protegidos, ¿por qué no decírselo? Les da una sensación de inocuidad y saben que nos interesamos por ellos. Hace que regresen con sus amigos".

El derecho del usuario a la privacidad y a la confidencialidad. La aplicación del COPE explora las muchas dimensiones del tema de la intimidad del usuario. Después del COPE, la Clinica Eastleigh se remodeló para que los usuarios pudieran recibir asesoria individual, en lugar que ésta se otorgara en salones con otras personas, y la mayoría de los establecimientos reconocen ahora la importancia de no interrumpir las sesiones de asesoria. "En realidad, soliamos entrar y salir durante las asesoría de los usuarios", afirma una enfermera, "pero ahora rara vez lo hacemos". El personal de Phoenix House también recuerda los dias cuando el expediente de uná mujer no era privado. "Los esposos solian venir aqui y hacer preguntas sobre las consultas de sus esposas, y soliamos informarles. Ahora no hacemos eso... Respetamos el derecho de la mujer a la confidencialidad y, al mismo tiempo, alentamos la participación y apoyo de la pareja".

El derecho del usuario a la continuidad. Dos de las principales causas de las altas tasas de discontinuación del uso de anticonceptivos son el suministro poco confiable de productos básicos y la frecuencia con que se agotan. Antes del COPE, la casa matriz no confiaba en que las clínicas mantuvieran los registros adecuados u ordenaran suministros a tiempo. Esto llevó a una tendencia de "empujar" suministros a las clínicas, provocando desmedidas existencias de algunos productos y desperdicios. Pero cuando se aplicó el COPE en el departamento de Almacenes Centrales, la situación empezó a mejorar.

\section{Llevar el COPE a los Mandos Superiores de la Organización}

Cuando se introdujo el COPE en las clínicas, el mal suministro de equipo y productos básicos solía aparecer como un problema importante. Como resultado de ello, la FPAK decidió emprender una aplicación modificada del COPE en la unidad de Almacenes Centrales de Nairobi. La aplicación reveló que el personal de la unidad estaba tan frustrado como el personal clínico con el sistema de organización de los servicios y suministros necesarios. "Nos deciamos que estábamos hartos de ser el muro de los lamentos de todo el mundo", afirma Timothy Kioko de Almacenes Centrales. Continúa:

"Nos encontrábamos en medio... las clínicas se quejaban, la casa matriz se quejaba y no podíamos ver nada positivo en nuestro trabajo. Pero cuando se nos explicó la importancia de nuestra labor y que teniamos que servir a nuestros clientes o de otro modo las mujeres sufririan, pusimos manos a la obra. ¿Cómo podemos hablar de un servicio de calidad si los productos no se entregan a tiempo? Ahora hacemos eso y tenemos el papel de gestores de calidad."

En este departamento, el proceso de creación de condiciones para la realización del potencial fue reforzado por la voluntad del personal de la casa matriz al atender las limitaciones de suministro que se encaraban y tomar conciencia de que debian modificarse los procesos. Millicent Kabugi, de Almacenes Centrales, recuerda: "Elaboramos nuevos formatos de requisición y de libro de mayor, convenimos con las clínicas en niveles mínimos de existencias y capacitamos al personal sobre la manera como debian comunicarse con nosotros... Las clinicas no tenían una gran planificación, pero ahora han mejorado... Las ayudamos, nos ayudaron, todo el mundo está mucho más tranquilo".

¡De hecho, el personal de la unidad Almacenes Centrales adquirió tantas facultades que se enfrentaron a la casa matriz de la IPPF en Londres! "Los productos básicos provenientes de Londres continuamente estaban a punto de caducar", explica Timothy Kioko.

"Desde luego, en el pasado sencillamente lo aceptábamos, nos sentiamos agradecidos por lo que recibiamos y nuestra actitud era: 'Bueno, estas personas de Londres son los grandes personajes, ¿quiénes somos nosotros para cuestionar lo que hacen?' Pero luego empezamos a aplicar el enfoque COPE para solucionar problemas y nos dimos cuenta que esto era algo que debiamos encarar. ¿Qué sentido tenía obtener estas cosas que no podíamos utilizar? El personal escribió una carta que explicaba el problema a la IPPF. El embarque más reciente tenía un tiempo de conservación de cinco años. Resolvimos el problema", afirma satisfecho Timothy.

Un nuevo sistema de abastecimiento ya ha resuelto 85 por ciento de los 41 problemas que el departamento de Almacenes Centrales enumeró en su primera aplicación del COPE. Han formado al personal clínico sobre cómo hacer pedidos de manera oportuna, cómo definir existencias de reserva y cómo aplicar el sistema de "primeras entradas-primeras salidas" (PEPS). (El PEPS es un método para organizar los productos básicos de tal modo que los primeros que se reciben son los primeros en utilizarse, de forma que se reduce la probabilidad de que expiren antes de que sean aprovechados). También ayudaron a las clínicas a coordinar sus suministros para apoyar mejor a los agentes de los PAC de la FPAK que hacian trabajo de campo. Rebecca Isiche, de la Clínica Riberio, explica: "El COPE nos ha alentado a descubrir más sobre los PAC en nuestra área, y ahora consideramos a los voluntarios como parte de nuestro equipo. Agradecemos el hecho de que nos traigan usuarios". 


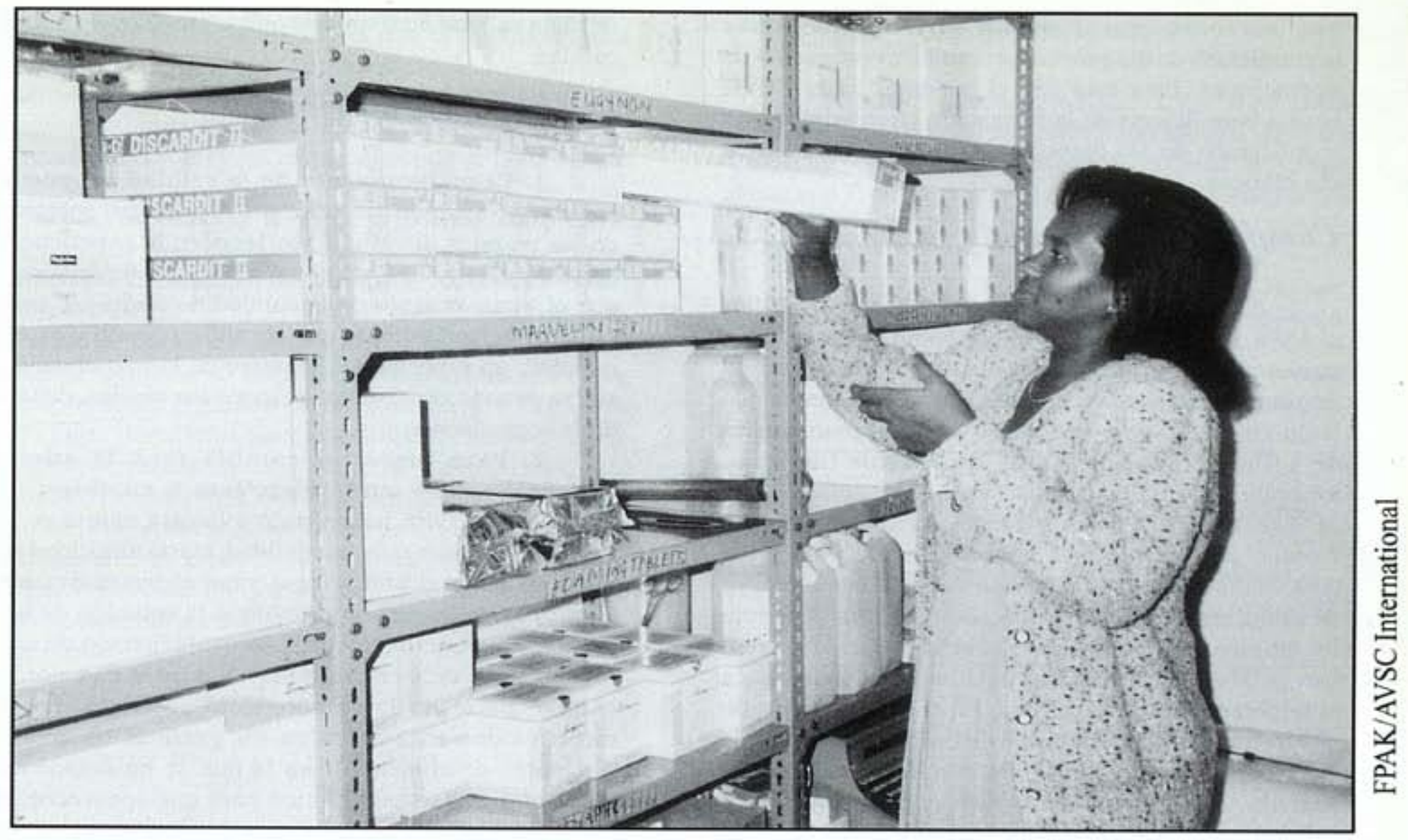

\section{De Cara al Futuro}

Como lo demuestra claramente la experiencia de la FPAK, el mejoramiento de la calidad no es un ejercicio único, sino un proceso continuo y en evolución constante. La FPAK ha estado trabajando en el mejoramiento de la calidad durante más de 10 años, empero, sólo en fechas recientes la organización ha empezado a apreciar un cambio real. Con todo, el trabajo aún no termina. Por ejemplo, la casa matriz de la FPAK aún no ha aprovechado el COPE para evaluar su propio desempeño. El hacerlo seria una expresión sincera de buena voluntad y podría ayudar a la casa matriz a respaldar a su personal de campo de manera más efectiva. Godwin Mzenge, director ejecutivo de la FPAK, señala que aún hacen falta 19 pasos para expedir un cheque en la casa matriz, así que están planeando aplicar el enfoque del COPE al analizar los procesos de su departamento financiero. La descentralización de la responsabilidad financiera -una cuestión de fondo en la reforma amplia del sistema- se encuentra aún en las etapas de planificación. Sin embargo, las perspectivas son buenas, en especial ahora que las clínicas han aumentado su base de ingresos no sólo debido a la nueva estructura tarifaria, sino dado el creciente número de usuarios.
Los salarios y prestaciones del personal, así como la sustitución de equipo costoso, son temas que se plantean con frecuencia durante la aplicación del COPE. A la fecha, estas cuestiones han sido del ámbito exclusivo de la administración central, pero ahora estos temas están también abiertos a debate. Se ha logrado cierto avance en la identificación de formas distintas a las monetarias para recompensar al personal, a través de iniciativas tales como el reconocimiento al "empleado del mes" y a "la clínica del año". La FPAK se complace con los resultados obtenidos hasta ahora en el enfoque de formación en el trabajo. Empero, la mayoría de los materiales y cursos existentes para la formación en planificación familiar se han elaborado para programas de formación centralizados y formales, de modo que los materiales disponibles deben revisarse minuciosamente y debe hacerse una nueva evaluación en cuanto a cómo se mide la capacidad, con el fin de que el personal pueda recibir el reconocimiento oficial de sus logros.

Hasta el momento, en Kenia, el programa ha subrayado de manera deliberada el diagnóstico de problemas y el aprovechamiento de herramientas muy sencillas que se concentran en cómo las personas realizan su trabajo. El proceso ha demostrado de manera clara que, además de identificar un problema, también debe diagnosticarse su causa y encontrarse una solución adecuada. Para hacer esto a escalas cada 
vez mayores, quizá deban introducirse otras herramientas de diagnóstico, como la investigación de operaciones. Para este fin, el personal de la FPAK podria beneficiarse de la formación en interpretación y aplicación de los datos que ya están acopiando en sus clínicas.

\section{Compartir lo Aprendido}

Al observar el éxito de la FPAK con el COPE, el MSK lo ha introducido ahora como parte del plan nacional para el mejoramiento de la planificación familiar en 22 de sus hospitales, y está planeando, a la larga, cubrir todos los hospitales y centros municipales de salud. "Tenemos frente a nosotros una gran aventura", afirma Jane Asila, "porque las aplicaciones de este tipo de técnica y estrategia son ilimitadas. Pueden emplearse (y se han empleado) para crear conciencia sobre otros temas en nuestras instituciones de salud, no sólo en la planificación familiar. Durante los últimos dos años, la FPAK y el Ministerio de Salud han colaborado en varias iniciativas regionales para el mejoramiento de la calidad. En el país, la inclusión de representantes del Consejo de Enfermeras de Kenia en talleres para el mejoramiento de la calidad ha logrado un mayor compromiso con iniciativas de calidad en la atención. Otras organizaciones, como la Asociación Cristiana de la Salud de Kenia, el Sector Privado de Planificación Familiar y Marie Stopes Internacional han adoptado también directrices similares para el mejoramiento de la calidad. Fuera de Kenia, el doctor Achwal ha trabajado con asociaciones de planificación familiar de Eritrea, Nigeria, Tanzania, Uganda y Zimbabwe, ayudándolas a adoptar directrices similares para el cambio.

\section{Calidad, ¿a qué costo?}

Cuando comenzó el proceso para el mejoramiento de la calidad, algunos miembros del personal de la FPAK sentían que seria costoso en cuanto al tiempo del personal e incomodidad de los usuarios. La aplicación del COPE tiene una duración de casi dos dias, pero la mayoría de los ejercicios se realizan mientras el personal sigue atendiendo a los usuarios y, como la responsabilidad se ha transferido gradualmente al personal local, los supervisores pasan menos tiempo en la gestión del proceso y más proveyendo apoyo técnico. Además, conforme el personal empezó a apreciar la solución de problemas antiguos en sus propias clínicas, cambió sus percepciones sobre el "costo". Ahora se dan cuenta de que debe pagarse un precio por no mejorar la calidad: usuarios insatisfechos, centros no aprovechados a plenitud, pérdida de negocios, desánimo del personal. En otras palabras, los servicios de mala calidad cuestan más que la atención de buena calidad.

\section{Las lecciones aprendidas}

1. El mejoramiento de la calidad no puede legislarse. Cuando fracasaron los primeros intentos de los mandos directivos por legislar, la experiencia enseñó, tanto a la FPAK como a AVSC Internacional, que el mejoramiento de la calidad no podía tan sólo ordenarse. Aprendieron que el cambio positivo es, en realidad, un proceso que requiere de la participación activa de todo el personal, de todos los niveles, dentro de la organización.

2. Para lograr el cambio real, la administración debe estar dispuesta a cambiar. El proceso del COPE ha ayudado a la casa matriz de la FPAK a aprender que, en realidad, cierta autoridad se ejerce mejor en el ámbito local, y que el personal puede contribuir de manera importante a la solución de los problemas. Por ello, la FPAK ha evolucionado de una organización muy centralizada a una en la que, por lo menos, parte de la responsabilidad financiera y directiva descansa ahora en los gerentes de área y directores de clínicas. $\mathrm{Y}$ en la que se ha dotado de facultades al personal clínico para que aproveche la información y las herramientas para mejorar el rendimiento.

3. El personal de todos los niveles, no sólo los prestadores de servicios, son capaces de asumir mayores responsabilidades y contribuir al proceso de cambio. Por ejemplo, la aplicación del proceso del COPE dentro del departamento de Almacenes Centrales tuvo importantes repercusiones en el mejoramiento de la calidad de los servicios en toda la organización. En el ámbito de las clínicas, la participación activa de otro personal de apoyo (por ejemplo, recepcionistas, afanadores y similares) ha permitido a estos empleados contribuir al programa de manera significativa, lo cual nunca antes se habían tomado en consideración.

4. Considerar a los usuarios como "clientes" y entender que tienen derechos, permite replantear la relación entre el usuario y el prestador. Este enfoque ha permitido a los prestadores ver las cosas desde la perspectiva de sus clientes y considerarlos "gente como uno". Desde ese punto de vista, hacer esperar a los clientes mientras todo el personal hacía una pausa para tomar el almuerzo, evidentemente, no era la forma de tratar al cliente. En el proceso, los clientes ya no son vistos como posibles fuentes de crítica, sino como aliados en la creación de una experiencia de trabajo más positiva.

5. Mejorar la calidad de los servicios no implica necesariamente mayores costos. E1 argumento más gastado para no cambiar la manera en 
que se prestan los servicios es que el cambio cuesta demasiado. Empero, la mayor parte de los cambios introducidos en la FPAK por la utilización del COPE suponen aumentar la eficiencia en el uso de los recursos existentes, en lugar de aumentar la inversión real en la prestación de servicios.

6. Involucrar a otras organizaciones en el proceso de cambio, la calidad de los servicios puede afectarse de manera más amplia, incluso al grado de contribuir a la creación de una estrategia nacional. La relación de apoyo mutuo de la FPAK con el Ministerio de Salud ha logrado más que simplemente legitimar esta obra. La planificación conjunta de talleres para la calidad, la elaboración y experimentación de herramientas y directrices, una comunicación y vínculos constantes, han beneficiado un amplio espectro de servicios de salud reproductiva en Kenia. Este cambio de perspectiva ya es evidente en el ámbito de aplicación nacional para mejorar la prestación de los servicios de planificación familiar en Kenia.

\section{Reconocimientos}

La autora desea agradecer a las siguientes personas su ayuda en la elaboración de este número: Godwin Mzenge, Isaac Achwal, Steven Mwangi, Margaret Thuo, al personal de la unidad de Almacenes Centrales; y a las clinicas Eldoret, Phoenix House, Thika, Nyeri, Ribeiro y Eastleigh, de la FPAK.

De AVSC Internacional: Joseph Dwyer, Grace Wambwa, Pamela Lynam, Karen Beattie, Cynthia Steele, Beverly Ben Salem y Ann-Marie Walker.

Para obtener más información sobre el COPE y otros enfoques para el mejoramiento de la calidad, asi como materiales elaborados por AVSC Internacional, póngase en contacto con Maj-Britt Dohlie, en AVSC Internacional, 79 Madison Avenue, NY, NY 10016 EU. 


\section{Epílogo}

Quizá la experiencia keniana documentada en este número de Quality/Calidad/Qualité sea singular, pero, cada vez en mayor medida, está siendo emulada en otras partes de la región. Los hombres y las mujeres de África, al sur del Sahara, participan ahora en un proceso de transformación y están asumiendo el control de su fertilidad en un mundo cambiante. Espero un futuro en el que los usuarios no sólo participarán de manera más activa en los servicios de gran calidad, sino que estarán dispuestos a pagarlos. En una época en la que está disminuyendo el financiamiento de los donadores, el reto de prestar servicios sostenibles de gran calidad es apremiante y real. Conforme nos acercamos al siglo XXI, los prestadores de servicios tendrán que proporcionar información y facilitar un proceso de toma de decisiones, fundamentado para los hombres, las mujeres y los jóvenes a los que atienden, en lugar de sólo distribuir anticonceptivos. En la medida en la que avanzamos hacia nuestra meta, queda mucho trabajo por hacer y hay nuevos retos por delante.

Aún cuando los servicios para los jóvenes se siguen considerando dificiles y polémicos, no podemos ignorar sus necesidades específicas en el área de la salud sexual y reproductiva. Los jóvenes representan uno de cada cinco hombres y mujeres en edad reproductiva en África, al sur del Sahara, sin embargo, están excluidos de la mayoría de los sistemas de prestación de servicios. El resultado de esta desatención se ha expresado trágicamente en la gran incidencia de embarazos adolescentes, abortos no protegidos e infecciones de transmisión sexual, incluso el VIH y el SIDA, entre nuestros jóvenes.

Por lo tanto, debemos pasar de la perspectiva estrecha de la instrucción de la vida en familia, a brindar programas y servicios de salud sexual y reproductiva integrales para los jóvenes. Aunque los Estados y las ONG de la región han tomado una mayor conciencia de estas necesidades, aún no han expresado su compromiso en cuanto a políticas y financiamiento. Si los jóvenes han de alcanzar su potencial pleno como individuos y ciudadanos del mañana, debemos asistirlos honesta y eficazmente sobre el tema de las necesidades sexuales y reproductivas.

Debemos abordar también las barreras médicas y legales que limitan el acceso a los servicios, y poner fin a prácticas tradicionales dañinas que impiden a las mujeres y a los jóvenes "en particular a las niñas", ejercer su derecho a disfrutar de relaciones sexuales voluntarias y protegidas. Debe fortalecerse en todo el continente, la promoción, por parte de la FPAK y otras ONG kenianas como Maeneleo y Wanawake, de iniciativas para eliminar la mutiliación genital femenina. Han recibido amplia difusión los estudios conjuntos como Women of the World: Laws and Policies Affecting Their Reproductive Lives, realizado por el Center for Reproductive Law and Policy (Nueva York) y la Internacional Federation of Women Lawyers (Sección de Kenia) [FIDA-K], en siete países de habla inglesa (Etiopía, Ghana, Kenia, Nigeria, Sudáfrica, Tanzania y Zimbabwe) ${ }^{5}$. Los programas nacionales deben ahora aprovechar esta información para derribar las barreras existentes en el acceso de las mujeres a la salud sexual y reproductiva protegida y no coercitiva.

También las percepciones de género deben tomarse en consideración e incorporarse en nuestros programas. Aunque los servicios para la mujer, y de fácil acceso para los jóvenes, deben seguir siendo prioritarios para nuestros programas y elementos novedosos, también deben abordarse el papel y la responsabilidad de los hombres en la salud sexual y reproductiva, con el fin de que ellos se conviertan en verdaderas parejas para la realización del potencial de las mujeres. En el oeste de Kenia, el programa de salud sexual y reproductiva y de tratamiento de infecciones de transmisión sexual para hombres, de la FPAK, es un paso positivo en ese sentido.

Por último, tenemos que plantear, analizar y revisar de nuevo la prestación de servicios de planificación familiar y los servicios de salud reproductiva relacionados en el advenimiento de la pandemia del VIH y SIDA. Es evidente que los servicios para los jóvenes ofrecen la posibilidad de intervención temprana antes de que la conducta sexual de riesgo se haya arraigado. Pero ¿qué hacer con quienes ya lo padecen? Los enfoques de asesoria comunitarios y la atención en el hogar contribuirán, en gran medida, a la reducción tanto del trauma psicológico de los individuos afectados, como de la onerosa carga de la epidemia en un sistema de salud, de por si, debilitado.

Las lecciones aprendidas gracias a la experiencia con el COPE han mejorado de manera formidable la imagen del prestador de servicios de la FPAK y sus organizaciones hermanas. Los usuarios satisfechos han corrido rápidamente la voz en Kenia, y otras instituciones están llamando a la puerta de la FPAK para solicitar formación en el uso del COPE. Por lo tanto, debemos crear un efecto multiplicador y ampliar los beneficios no sólo en todo Kenia, sino en los paises de África, al sur del Sahara. Para la mayoría de los usuarios de África los servicios de calidad siguen siendo un sueño. El ejemplo dado por la FPAK y su red, junto con AVSC Internacional y la IPPF, debe ser imitado en otros paises. El ejemplo keniano demuestra que el logro de la atención de calidad y la conformación de una cultura de evaluación propia, y de verdadera participación del personal, es asequible, alcanzable y sostenible en el contexto africano. 


\section{Notas}

2. Para obtener un resumen de este enfoque, consultar Dwyer, J. y T. Jerzowski, "Quality Management for Family Planning Services: Practical Experience from África", AVSC Working Paper Num. 7, febrero de 1995, AVSC Internacional, Nueva York.

3. Huezo, Carlos y Soledad Díaz, "Quality of Care in Family Planning: Clients' rights and provider needs" en Advances in Contraception 9:129-139, 1993.
4. Consultar IPPF, Londres, Medical and Service Delivery Guidelines, $2^{\mathrm{a}}$ edición, IPPF, Londres, 1997.

5. The Center for Reproductive Law and Policy, Inc., y la Internacional Federation of Women Lawyers (Sección de Kenia), FIDA-K, Women of the World: Laws and Policies Affecting Their Reproductive Lives, Anglophone Africa, The Center for Reproductive Law and Policy, Nueva York, 1997. 


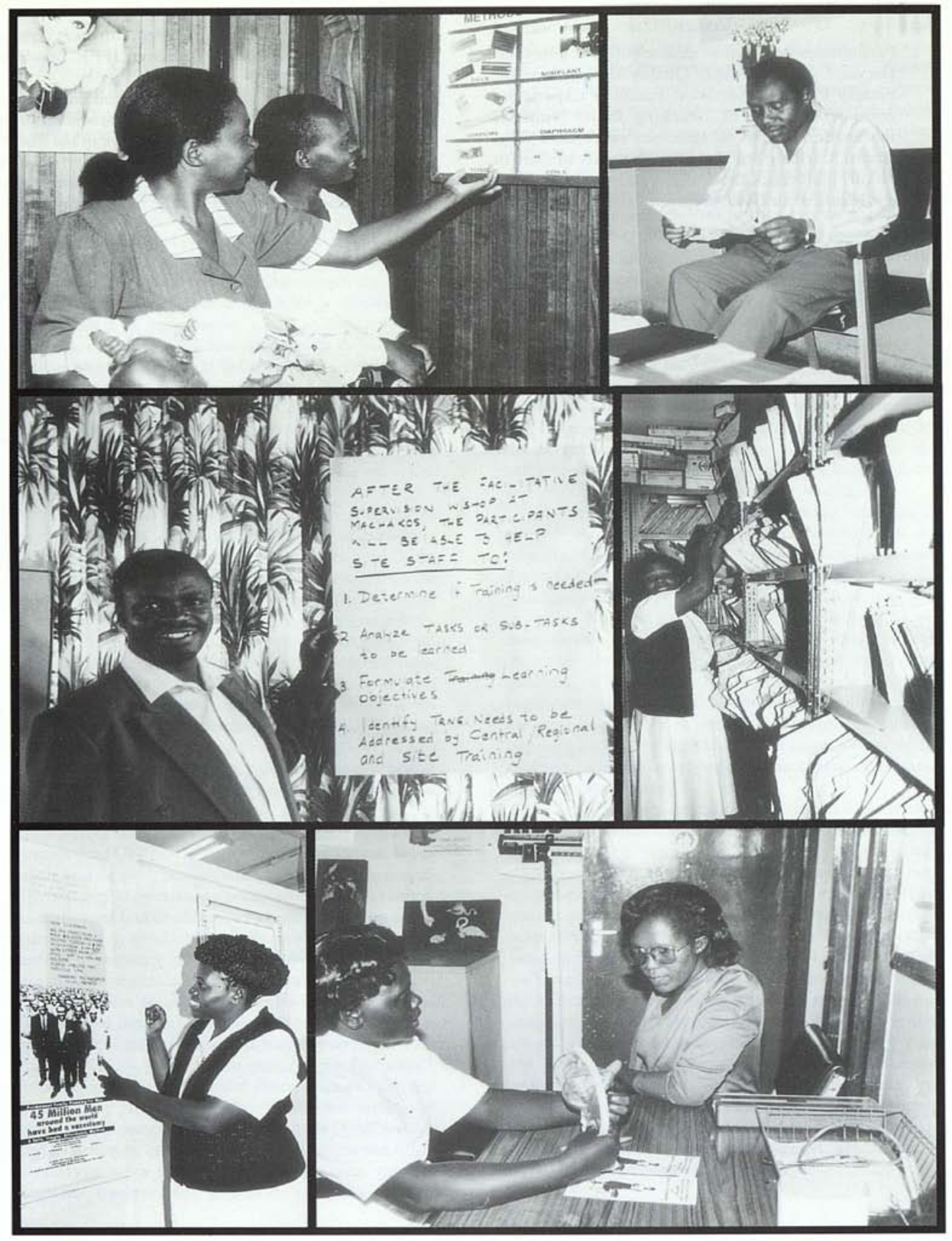




\section{Résumé en français}

Avis au leucteur: Cette publication porte sur l'exercice COPE (client-oriented, provider efficient, services efficaces axés sur le client) de l'AVSC International. Le COPE est un outil d'auto-évaluation qui a été utilisé dans 35 pays, et cette publication examine son emploi par l'association kenyane de planification familiale (FPAK, Family Planning Association of Kenya). Il s'agit de la première d'une série d'éditions décrivant les diverses méthodes qui permettent aux programmes de planification familiale d'évaluer la qualité de leurs services.

La FPAK, organisation affiliée à la fédération internationale pour la planification familiale (IPPF), gère 14 centres de santé au Kenya, soit 250 employés rémunérés travaillant à plein temps et un réseau de plus de 1000 agents bénévoles. Au départ, la FPAK mettait l'accent sur le développement structurel et les objectifs démographiques. Toutefois, au milieu des années 1980 , elle a commencé à déplacer son centre d'intérêt, l'importance de l'offre de soins de qualité se faisant de plus en plus sentir. Les premières tentatives pour résoudre les problèmes n'étaient pas encourageantes, car personne ne voulait prendre la responsabilité des problèmes identifiés.

Dans le même temps, l'AVSC International essayait un nouvel outil d'évaluation appelé COPE (sigle de client-oriented, provider-efficient). La FPAK a accepté d'essayer cette nouvelle méthode pour résoudre les problèmes de qualité des soins. Les exercices COPE conprennent quatre outils fondamentaux : des guides d'auto-évaluation, des entrevues avec les clients, une analyse de l'acheminement des clients (en vue de déterminer les délais d'attente) et un plan d'action rédigé par le personnel, en se basant sur les résultats des trois autres outils d'évaluation.

Il s'est cependant avéré que la première version de COPE était trop axée sur les outils et des services particuliers des cliniques, et non pas sur le personnel ou les besoins des clients. Par ailleurs, étant donné que les conclusions des exercices COPE étaient directement transmises aux sièges, on continuait d'accuser ou de rejeter la responsabilité des problèmes sur des individus. La FPAK s'est alors rendu compte que le problème provenait non pas des personnes, mais plutôt du système dans lequel ces derniers travaillaient, à savoir un système trop centralisé, n'encourageant pas le personnel, et le punissant parfois. II fallait adopter une nouvelle approche qui accorderait au personnel le pouvoir d'agir et qui le soutiendrait, plutôt que de le blâmer.

L'AVSC, en collaboration avec la FPAK, a done reformulé le COPE. La nouvelle approche insistait sur le fait que les outils d'amélioration de la qualité devaient être utilisés par le personnel des centres et non pas par les superviseurs. A cet effet, on a appris au personnel à faire les exercices COPE, et les rapports n'étaient plus envoyés aux sieges. Les conclusions sont ainsi devenues la propriété du personnel des centres. Ce dernier, ne craignant plus d'etre reprimandé, a commencé à analyser les problèmes en toute liberté et à envisager ses propres solutions. La FPAK lui a également donné plus de pouvoir concernant de nombreuses activités. En conséquence, les prestataires de services, qui n'avaient plus peur d'assumer des responsabilités, se sont sentis plus appréciés par l'organisation.

Actuellement, le personnel à tous les niveaux assiste et participe aux exercices COPE. Certains membres du personnel étaient initialement surpris que des chauffeurs, des jardiniers et le personnel de nettoyage soient conviés aux réunions ; ils constatent à présent que ces personnes peuvent aussi contribuer à assurer le succès de la méthode. Le personnel de nettoyage joue désormais un rôle primordial dans le maintien d'un environnement stérile. Les jardiniers et les gardiens, pour leur part, sont en mesure de donner une orientation de base en matière de planification familiale aux éventuels clients, surtout les hommes.

En outre, la nouvelle approche COPE soutient les droits des clients. Elle fait en sorte que les prestataires s'identifient naturellement avec leurs clients et cherchent à connaître leurs réactions. "Ici, nos clients se sentent acceptés. Ils estiment qu'ils sont traités avec respect et ils sont contents de pouvoir s'exprimer librement," remarque un prestataire. "Les clients nous disent qu'ils ont constaté des améliorations, (cela) me pousse à faire beaucoup plus," ajoute une infirmière.

Au début, certains membres du personnel de la FPAK pensaient que l'amélioration de la qualité des soins coûterait cher, mais deux jours suffisent pour faire les exercices COPE et la plupart d'entre eux peuvent être effectués pendant que le personnel sert les clients. Ces membres du personnel s'aperçoivent maintenant que le fait de ne pas améliorer la qualité des services entraîne de nombreuses conséquences: clients insatisfaits, centres de santé insuffisamment utilisés, manque de clients et personnel démoralisé.

L'expérience de la FPAK relative à l'emploi de la méthode COPE permet de tirer certains enseignements, notamment que : 1) le changement positif est un processus continu qui nécessite la participation active de tout le personnel à tous les niveaux ; 2) certains types de pouvoirs sont mieux exercés par le personnel local que par l'administration centrale; 3 ) tous les employés, et pas seulement les prestataires de services, peuvent assumer plus de responsabilités ; 4) le fait de considérer les patients comme des clients ayant des droits peut aider à 
redéfinir la relation entre le client et le prestataire et 5 ) en impliquant d'autres organisations dans le processus de changement, on peut améliorer la qualité des services sur une plus grande échelle et même contribuer à l'élaboration d'une stratégie nationale globale. 


\section{Sobre los Autores}

Jan Bradley es investigadora en salud de la población, con capacitación en administración, planeación y políticas de servicios de salud. De 1983 a 1996 trabajo en Nairobi, Kenya como consultora para varias agencias locales e internacionales. Desde principios de 1998, ha sido Miembro Investigador de la AVSC Internacional.

Judith Bruce es Asociado principal en la División de Programas Internacionales del Population Council en New York. Soledad Diaz es Investigador principal en la Unidad de Investigación de Servicio Social del Instituto Chileno de Medicina Reproductiva en Santiago, Chile. Carlos Huezo es Director Médico de la Federación Internacional de Paternidad Planeada (IPPF), con base en Londres.

Kalimi Mworia es Director Regional Miembro en la Mobilización de Recursos y Apoyos de la Oficina Regional de IPPF en Africa y antiguo Director Ejecutivo de la Asociación de Planeación Familiar en Kenya.

\section{Grupo de Asesores de Quality/Calidad/Qualité}

Ian Askew

Karen Beattie

Martha Brady

George Brown

Judith Bruce

Charlotte Gardiner

Adrienne Germain
Geeta Rao Gupta

Nicole Haberland

Joan Haffey

Judith Helzner

Ann Leonard

Magaly Marques

Elizabeth McGrory
Kirsten Moore
Nancy Newton
John Paxman
Julie Reich
Deborah Rogow
Jill Sheffield
Cynthia Steele

Karen Stein

Nahid Toubia

Gilberte Vanintejan

Beverly Winikoff
Foto de la Portada:

Tipografía e

impresión:

Coordinación editorial y de producción de la versión en inglés:
Ann Leonard

mas impresos

Diane rubino

\section{Ejemplares Disponibles Actualmente de Quality/Calidad/Qualité}

Celebrating Mother and Child on the Fortieth Day: The Sfax Tunisia Postpartum Program por Francine Coeytaux, Introducción y Conclusiones por Beverly Winikoff, 1989. (Disponible en inglés; texto en español y francés disponible en formato mecanografiado)

Man/Hombre/Homme: Meeting Male Reproductive Health Care Needs in Latin America por Debbie Rogow; Introducción y Conclusiones por Judith Bruce y Ann Leonard, 1990.(Disponible en inglés y español)

Gente Joven/Young People: A Dialogue on Sexuality with Adolescents in Mexico por Magaly Marques, Introducción por John M. Paxman y Conclusiones por Judith Bruce, 1993. (Disponible en inglés y español)

The Coletivo: A Feminist Sexuality and Health Collective in Brazil por Margarita Diaz y Debbie Rogow, Introducción por José Barzelatto, 1995. (Disponible en inglés, portugués y español)

Doing More with Less: The Marie Stopes Clinics of Sierra Leone por Nahid Toubia, Introduccion por Grace Eban Delano, 1995. (Disponible en inglés)

Introducing Sexuality within Family Planning: The Experience of Three HIV/STD Prevention Projects from Latin America and the Caribbean por Julie Becker and Elizabeth Leitman, Introducción por Mahmoud F. Fathalla, 1997. (Disponible en inglés y español)

(Cada edición en inglés contiene un resumen de una página en frances y español)

Le invitamos a enviar sus comentarios e ideas sobre proyectos que pudieran ser incluídos en próximas ediciones de Quality/ Calidad/Qualité Si desea ser incluido en nuestra lista de direcciones, por favor escriba a: Quality/Calidad/ Qualité, Population Council, One Dag Hammarskjold Plaza, New York, NY 10017 USA, o correo electrónico pubinfo@popcouncil.org 
